\title{
Impact of value-at-risk models on market stability
}

\author{
Bàrbara Llacay ${ }^{\mathrm{a}, \mathrm{b}, 1}$, Gilbert Peffer ${ }^{\mathrm{a}, \mathrm{b}}$ \\ ${ }^{a}$ Centre Internacional de Mètodes Numèrics en Enginyeria (CIMNE), Campus Nord UPC, Gran Capità, \\ s/n, 08034 Barcelona, Spain \\ ${ }^{\mathrm{b}}$ Dept. for Economic, Financial, and Actuarial Mathematics, University of Barcelona, Av. Diagonal 690, \\ 08034 Barcelona, Spain.
}

\begin{abstract}
Financial institutions around the world use value-at-risk ( $\mathrm{VaR})$ models to manage their market risk and calculate their capital requirements under Basel Accords. VaR models, as any other risk management system, are meant to keep financial institutions out of trouble by, among other things, guiding investment decisions within established risk limits so that the viability of a business is not put unduly at risk in a sharp market downturn. However, some researchers have warned that the widespread use of VaR models creates negative externalities in financial markets, as it can feed market instability and result in what has been called endogenous risk, that is, risk caused and amplified by the system itself, rather than being the result of an exogenous shock. This paper aims at analysing the potential of VaR systems to amplify market disturbances with an agent-based model of fundamentalist and technical traders which manage their risk with a simple VaR model and must reduce their positions when the risk of their portfolio goes above a given threshold. We analyse the impact of the widespread use of VaR systems on different financial instability indicators and confirm that $\mathrm{VaR}$ models may induce a particular price dynamics that rises market volatility. These dynamics, which we have called 'VaR cycles', take place when a sufficient number of traders reach their VaR limit and are forced to simultaneously reduce their portfolio; the reductions cause a sudden price movement, raise volatility and force even more traders to liquidate part of their positions. The model shows that market is more prone to suffer VaR cycles when investors use a short-term horizon to calculate asset volatility or a not-too-extreme value for their risk threshold.
\end{abstract}

Keywords: Value-at-risk; agent-based simulation; financial instability; volatility; risk limit; volatility window

JEL Classification: C63; G1; G01; G20; G11; G17

\section{Introduction}

Financial institutions around the world use value-at-risk (VaR) models to measure their market risk (Feridun, 2005). This type of models were first used in Wall Street in the late 80s (Triana, 2010), and after the launch in 1994 of the RiskMetrics VaR methodology by JP Morgan, they have become the mainstream methodology for financial risk management ( (IMF, 2007), (McNeil, Frey, \& Embrechts, 2005)), as well as a fundamental part of the Basel Capital Accords since the 1996 Amendment on market risks (Shin, 2010).

\footnotetext{
${ }^{1}$ Corresponding author at: Centre Internacional de Mètodes Numèrics en Enginyeria (CIMNE), Campus Nord UPC, Gran Capità, s/n, 08034 Barcelona, Spain. E-mail address: 1lacay@ cimne.upc.edu.
} 
VaR measures the maximum loss that an asset portfolio may suffer over a specific horizon and with a given level of confidence (Choudhry, 2006). For example, if the daily VaR of a portfolio is $€ 1$ million at $95 \%$ confidence, this means that the probability that daily losses are higher than $€ 1$ million is $5 \%$. VaR constitutes an intuitive measure that was initially used to communicate financial risks to managers in an easy, understandable way; however, over time it has also been universally adopted to set position limits to traders, to allocate capital among different trading units, or to calculate the regulatory capital required under Basel Accords (Jorion, 2001).

VaR models, as any other risk management system, are meant to keep financial institutions out of trouble by, among other things, guiding investment decisions within established risk limits so that the viability of a business is not put unduly at risk in a sharp market downturn. However, some researchers have warned that the widespread use of VaR models creates negative externalities in financial markets, as it can feed market instability and result in what has been called endogenous risk, that is, risk caused and amplified by the system itself, rather than being the result of an exogenous shock (Danielsson \& Shin, 2002). Financial institutions usually set VaR limits to their traders or units, which are forced to reduce their positions when the risk exceeds these limits; when volatility increases, the VaR of trading portfolios also goes up and so traders can be forced to reduce their positions, but their sales can cause a price drop and so a new volatility upsurge, triggering further portfolio reductions. When many investors hold similar positions and also use the same type of risk management models, they may be forced to simultaneously sell the same assets, leading to an instabilising spiral ( (Danielsson, et al., 2001), (Persaud, 2000)).

A paradigmatic example of this type of process is the turmoil that hit mature financial markets in Summer 1998 and which in the end led to the downfall of LTCM, one of the most successful hedge funds at the time ( (Davis, 1999), (Perold, 1999)). The Russian default on 17 August 1998 forced the investors with exposure to the ruble debt market to liquidate positions to purchase safer, more liquid assets. This flight-to-quality raised the price of most liquid assets and plunged the price of illiquid ones (MacKenzie, 2003). The spread widening caused significant losses to LTCM and to the numerous investors that in previous years had imitated LTCM's strategies dazzled by their impressive returns ( (BIS, 1999), (MacKenzie, 2003)). Some of these investors were forced to further reduce their portfolios, resulting in a self-feeding spread widening. The mounting losses brought LTCM to the brink of collapse, and only a rescue organised in extremis by the Fed was able to avoid its failure and the subsequent systemic crisis that it would certainly have caused (IMF, 2007).

In a report on the events of 1998 (BIS, 1999), the Committee on the Global Financial System of the Bank for International Settlements provides a telling account of the deficiencies in current risk management methodologies, which were perceived by market participants to have played a major role in the 1998 crisis. According to the BIS findings, the ubiquitous use of VaR-based risk management tools might have contributed to no small extent to the propagation of initially localised disturbances. This concern was shared by all interviewed market participants, who described how the increase in $\mathrm{VaR}$ due the higher volatility forced many investors to reduce simultaneously their exposure, thereby draining liquidity from the markets and raising the upward pressure on volatility.

So risk management control such as that proposed by the Basel Accords can, paradoxically, facilitate the contagious spread of instabilities, because they contribute to synchronise the 
behaviour of market participants, which may be forced to liquidate part of their positions simultaneously ( (IMF, 2007), (Whitehead, 2013)). The impact of these liquidations would be negligible if investors had very different portfolios, as the selloffs by some agents would have no effect on those with different positions. Nevertheless, there is empirical evidence that financial institutions such as hedge funds and big banks accumulate similar positions ( (Pericoli \& Sbracia, 2010), (Haldane \& May, 2011)), and diverse regulators have warned of the risk this may pose to the liquidity of those markets where they invest ( (Bank of England, 2004), (ECB, 2007)). In particular, this concern was raised during the hearing held by the U.S. House of Representatives in September 2009 to elucidate the role that risk-management systems and specially VaR played in credit crunch of 2007-08:

"[A]sset-pricing and risk management tools are developed from an individualistic perspective, taking as given (ceteris paribus) the behavior of all other market participants. However, popular models might be used by a large number or even the majority of market participants. Similarly, a market participant (e.g., the notorious Long-Term Capital Management) might become so dominant in certain markets that the ceteris paribus assumption becomes unrealistic. The simultaneous pursuit of identical micro strategies leads to synchronous behavior and mechanic contagion. This simultaneous application might generate an unexpected macro outcome that actually jeopardizes the success of the underlying micro strategies." (Colander, 2009, p. 10)

This paper aims at analysing the potential of VaR systems to amplify market disturbances with an agent-based model where traders set position limits and must reduce their positions when the VaR of their portfolio is above the limit ${ }^{2}$. As seen above, we are not the first to warn on the detrimental effects that the widespread use of risk management systems can have in market stability, but we are able to analyse their impact on different instability indicators and to study under which conditions the market is more prone to show turmoil episodes.

In recent years, a few equilibrium-based models have already been developed to study the link between risk constraints and heightened volatility. Danielsson, Shin and Zigrand (2004) consider a continuum of risk-averse traders that determine their portfolio to maximise their next-period utility. A risk contraint is incorporated in the model through traders' beliefs, which are affected by the variance of past returns, and the results show that the widespread use of this type of risk contraint exacerbates market volatility. The authors reach a similar conclusion with a rational expectations model of stochastic volatility (Danielsson, Shin, \& Zigrand, 2009) where risk-neutral agents maximise their expected returns subject to a VaR constraint. Tasca and Battiston (2012) consider a balance sheet approach where traders maintain a constant leverage level, which is equivalent to maintaining a constant VaR level; this creates a positive feedback between prices and leverage that amplifies shocks in prices and results in higher systemic risk when the price is very responsive to traders' action.

\footnotetext{
${ }^{2}$ This process has similarities with the loss spirals identified by Brunnermeier and Pedersen (2009), which affect market liquidity: when investors are leveraged and their assets lose value, their losses mount and leverage goes up. In order to continue getting access to credit it is necessary to have a minimum margin, and thus there is a limit on their leverage level. To keep a constant level of leverage and avoid surpassing this limit, investors are forced to reduce their portfolio, what may move prices in an unfavourable direction (the more illiquid the market, the greater the impact in prices) and cause new lossses. This dynamics gives rise to a loss spiral.
} 
The study of the effects of risk constraints on market dynamics is related to the literature on the leverage cycle. The seminal paper by John Geanakoplos (1997), further developed in subsequent contributions ( (2003), (2009)) provides a leverage cycle theory based on collateral general equilibrium model with incomplete markets. A key factor in these models is the heterogeneity in agents' beliefs: optimistic investors are natural buyers, and they leverage their positions thanks to the credit provided by less optimistic investors. But when bad news come, the shock is amplified through two mechanisms: a redistribution of wealth from optimistic to pessimistic agents, and a negative impact in average expectations. Fostel and Geanakoplos (2008) extend this model to show that a leverage cycle in one asset class can extend to different, unrelated asset classes. Hoelle (2016) also considers a multi-asset version of the Geanakoplos model framework to analyse the effect of dependent beliefs on endogenous leverage. The leverage cycle can also be explained by the use of VaR-like rules. Adrian and Shin (2013) explore with a simple contract model the procyclical relationship between leverage of financial intermediaries and credit supply and show that the leverage cycle can be caused by the use of risk management rules by financial intermediaries. Adrian and Boyarchenko (2012) also study the link between intermediary leverage cycle and risk-based capital constraints with a dynamic general equilibrium model of the macroeconomy where - in contrast to Geanakoplos model markets are complete and debt contracts are not collateralised. Thurner (2012) provides another perspective on the leverage cycle with an agent-based model where value investors can borrow to leverage their traders, and they find that this behaviour results in fat tails and clustered volatility. Aymanns and Farmer (2015) indirectly study the effect of VaR constraints by means of a model where fundamentalist investors set a maximum leverage limit which is linked to a $\mathrm{VaR}$ limit, and show that market dynamics turn out to be countercyclical (procyclical) when leverage is (inversely) proportional to volatility. Aymanns et al. (2016) build on the previous model to study the effect of different regulations on the leverage cycle.

Some agent-based models have dealt with the impact of VaR systems. These models allow to go beyond the limitations of equilibrium-based models as they make it possible to model complex interactions among heterogeneous, bounded-rationality agents ( (Bookstaber, 2012), (Trichet, 2011)). Takahashi (2013) focuses on the impact of VaR systems on market efficiency and his simulations with a fundamentalist-only population show that the stricter agents are in their risk management, the bigger the distance between the price and the fundamental value. Faria and Phelps (2011) and Faria (2012) explore the effect of VaR limits à la Basel III on market stability, considering a population of agents with a richer behaviour: they maximise their utility based on expectations that combine a fundamental and a technical component with a genetic algorithm. The authors conclude that the introduction of VaR restrictions can force agents to reduce their positions simultaneously and increases market volatility. Hermsen (2010) presents a model where traders use a fundamentalist or technical strategy subject to Basel II regulation and results similarly show that instability increases when the proportion of regulated agents goes up.

From a more general perspective, this paper can be inscribed in a wider field within heterogeneous agent models aimed at identifying the mechanisms behind market bubbles and crashes. Different explanations have been provided for the boom and bust dynamics, which in rough outlines revolve around two types of mechanisms: variable populations of agents, due e.g. to imitation, herding, or switching between strategies in search of higher profits (e.g. (Brock \& Hommes, 1998), (Chen \& Yeh, 2001), (De Grauwe \& Grimaldi, 2004), (Lux, 1995) or 
(Westerhoff, 2009)) or the presence of financial constraints as in the present paper (see e.g. (Duffy \& Ünver, 2006), (Thurner, Farmer, \& Geanakoplos, 2012)).

Relative to the previous literature on the effect of risk constraints, our paper has a variety of strengths in the model calibration and analysis: we are not only interested in showing that VaR constraints can contribute to increase market instability, but will study how the different parameters of a VaR model impact on market dynamics; our base model has been previously calibrated to reproduce the most important stylised facts of stock markets (Llacay, 2015) to increase the validity of our results; finally, we do not only focus on market volatility as a proxy of market instability, but we analyse a range of different instability indicators to provide a wider perspective on market behaviour under VaR constraints.

The remainder of the paper is organized as follows. In section 2 we present our agent-based model and describe how market stability will be measured. In section 3 we use the model to study the effect of VaR position limits on the price dynamics and the market stability, and section 4 then concludes our discussion.

\section{Model description}

We consider a market for a single risky asset - a stock - in unrestricted supply, where traders place orders at discrete trading intervals, changing the composition of their investment portfolios in accordance with their respective valuation model and, in the case where portfolio risk limits apply, with a Value-at-Risk (VaR) model.

\subsection{Price formation}

The price $P_{t}$ for the stock is set by a market maker in accordance to a linear price formation rule. Although other formulations are possible (see e.g. (Madhavan, 2000) for a survey), we use the simplest one, which states that prices have to rise (fall) in the presence of over-demand (oversupply) by an amount that is inversely proportional to the liquidity of the traded security. Here, we do not take into account the inventory of the market maker nor the presence of information asymmetries in the market, and thus assume bid-ask spreads to be zero. Stock price is updated according to:

$$
P_{t}=P_{t-1}+\frac{1}{\lambda} \cdot \Theta_{t-1}+\xi_{t}
$$

where

- $\Theta_{t-1}$ is the total excess order, that is the sum of all orders emitted in $t-1$

- $\lambda$ is a constant liquidity factor that accounts for the depth of the market

- $\xi_{t}$ is a random term, $\xi_{t} \sim N\left(0, \sigma_{P}\right)$, that accounts for the random perturbations - such as the arrival of new information - that can possibly affect the market-maker's decision making process.

One disadvantage of this linear formulation is that prices can become negative, which could be avoided by using a log-price formulation for the price discovery rule. Outstanding orders in any 
given trading interval are always filled at the quoted prices and the market maker absorbs the excess or covers the shortfall, adjusting the prices according to the impact function ( 1 ).

\subsection{Trading strategies}

In stock markets, two main investment approaches can be identified (Bonenkamp, 2010):

- Fundamentalist trading - Fundamentalist investors argue that assets have an intrinsic value, which can be determined with a detailed analysis of the characteristics of the asset, its issuer and the market (Murphy, 1999). The price is expected to move around the fundamental value, so when both diverge an investment opportunity appears: if the value exceeds the price the asset is said to be overvalued and it should be bought; if the value is lower than the price, then it should be sold (Malkiel, 1973).

- Technical analysis - This aproach builds on the analysis of past price movements to infere its future evolution. It claims that markets are driven by psychological factors which reflect investors' hopes and fears - rather than fundamentals (O'Neill, 2011). Technical analysis is much more recent than fundamentalist trading; its use largely spread since the $60 \mathrm{~s}$ and is has come to dominate the most modern and liquid markets (Johnson, Jefferies, \& Ming Hui, 2003).

Building on these trading approaches, we consider in the model two types of investors: fundamentalist traders (FUND) and technical traders (TREND). This combination of strategies is relatively frequent in agent-based models of financial markets as these are the mainstream trading approaches in stock markets (see, for example, (Arthur, Holland, LeBaron, Palmer, \& Tayler, 1996), (Lux \& Marchesi, 2000) or (Farmer \& Joshi, 2002)). We describe next in detail how we implement both types of agents in our model.

\subsubsection{Fundamentalist traders (FUND)}

Our implementation of the fundamental strategy is based on (Farmer \& Joshi, 2002). Fundamentalist investors derive the intrinsic value of the stock from a private, exogenous signal they receive before each trading period. This exogenous signal is modelled as a random walk $V_{t}$, plus an agent-specific constant $v^{f}$ that accounts for the variability in the perception of the fundamental value:

$$
V_{t}^{f}=V_{t}+v^{f}, \text { where } V_{t}=V_{t-1}+\eta_{t},
$$

where $\eta_{t}$ is drawn from a normal distribution with constant variance, $\eta_{t} \sim N\left(0, \sigma_{V}\right)$, and the agent-specific constant $v^{f}$ is set at the start of the simulation from a uniform distribution, $v^{f} \sim U\left(v_{\min }, v_{\max }\right)$, with $v_{\min }=-v_{\max }$.

The positions of fundamentalist traders are proportional to the difference of actual price $P_{t}$ to perceived fundamental value $V_{t}^{f}$. However, an agent only enters a position when the different between price and value is above a given threshold, $\left|V_{t}^{f}-P_{t}\right|>T^{f}$. In that case, the position is determined as $^{3}$ :

\footnotetext{
${ }^{3}$ This implementation of the fundamental strategy is based on (Farmer \& Joshi, 2002).
} 


$$
\operatorname{pos}_{t}^{f}=V_{t}^{f}-P_{t} .
$$

Let's note that when the price lies above the fundamental value, the asset is overpriced and the agent decides to sell; when the price lies below the fundamental value, then the agent decides to buy.

Fundamentalist investors keep their positions open until the price and the fundamental value converge, that is, until their difference is smaller than a given threshold. In that case, the agents liquidate their position:

$$
\begin{aligned}
& \text { If } \operatorname{pos}_{t-1}^{f}>0 \& V_{t}^{f}-P_{t}^{f}<\tau^{f} \text { then } \operatorname{pos}_{t}^{f}=0 . \\
& \text { If } \operatorname{pos}_{t-1}^{f}<0 \& V_{t}^{f}-P_{t}^{f}>-\tau^{f} \text { then } \operatorname{pos}_{t}^{f}=0 .
\end{aligned}
$$

In case an agent has an open position, but the liquidation condition is not satisfied, then it simply updates its position based on the diference between price and value: if this difference has reduced (widened) since the position was opened, then the investors also reduces (increments) its position:

$$
\operatorname{pos}_{t}^{f}=V_{t}^{f}-P_{t} \text {. }
$$

Fundamentalist investors are heterogeneous in their entry and exit thresholds

$$
T^{f} \sim U\left(T_{\min }, T_{\max }\right), \quad \tau^{f} \sim U\left(\tau_{\min }, \tau_{\max }\right) .
$$

Once determined the new position, the agent calculates the order to be sent to the market-maker:

$$
\theta_{t}^{f}=\operatorname{pos}_{t}^{f}-\operatorname{pos}_{t-1}^{f} .
$$

Figure 1 summarises how the fundamentalist strategy works:

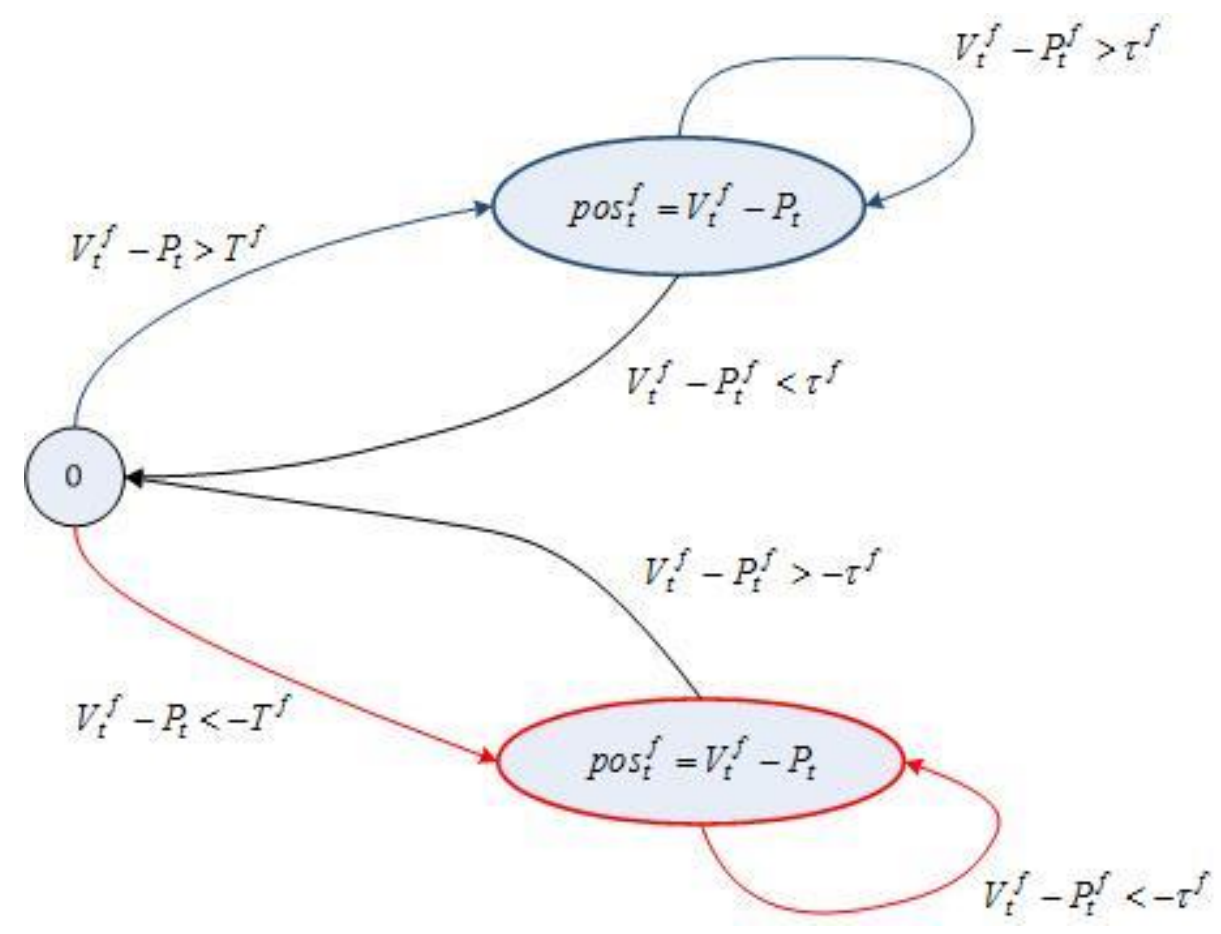




\subsubsection{Technical traders (TREND)}

Technical traders exploit price trends, and for that aim we have implemented two of the most common techniques in real markets (Taylor S. , 2005): to detect the start of a trend in prices, agents compare a short- and a long-term moving average of past prices; to detect the end of a price trend, agents rely on the technique of channel breakouts. To implement these rules, we have built on the practitioner literature, mainly on the description provided in (Kestner, 2003).

At each time step, technical investors calculate two simple moving averages (MA) of past prices: one short-term MA that responds quickly to recent price movements, and a long-term MA that responds more slowly. Let $w_{S}^{t r}$ and $w_{L}^{t r}$ be the windows used by the technical agent $t r$ to calculate his short- and long-term moving averages, respectively. The moving averages are then given by:

$$
\begin{aligned}
& M A\left(w_{S}^{t r}\right)_{t}=\frac{1}{w_{S}^{t r}} \cdot \sum_{i=t-w_{S}^{t r}+1}^{t} P_{i} \\
& M A\left(w_{L}^{t r}\right)_{t}=\frac{1}{w_{L}^{t r}} \cdot \sum_{i=t-w_{L}^{t r}+1}^{t} P_{i}
\end{aligned}
$$

When the two moving averages cross, it is the key time to buy or sell: if the short-term MA crosses the long-term MA from below, the agent interprets it as the beginning of an upward trend and opens a long position; if the short-term MA crosses the long-term MA from above, the agent interprets it as the start of a downward trend and opens a short position (Figure 2). 


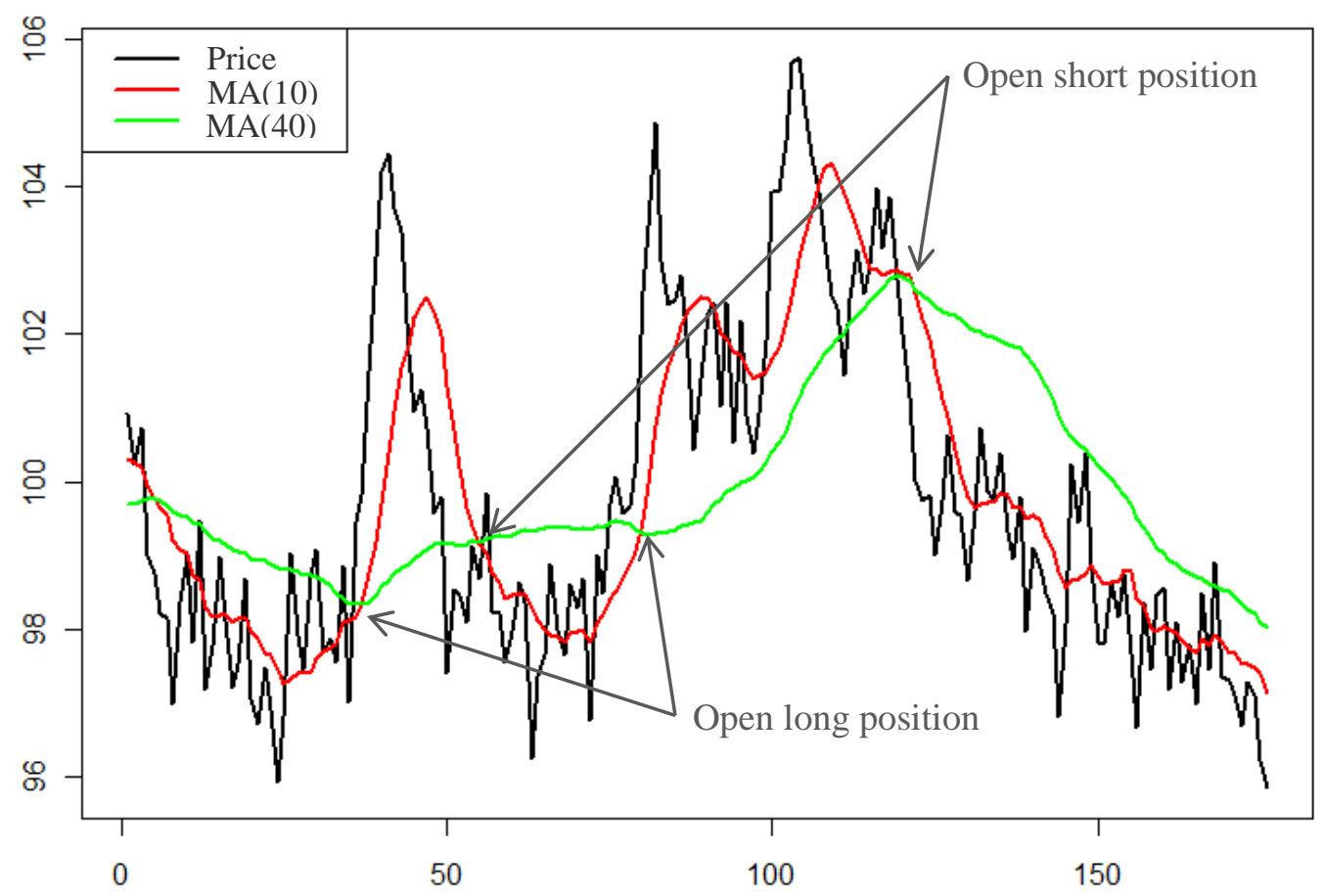

Figure 2 - Illustration of the behaviour of long- and short-term moving averages

When the MA's cross and the agent opens a position, it is proportional to the difference in slope between the two moving averages, because it is assumed that the greater this difference, the steeper the upward or downward price trend. Equations ( 8 ) and ( 9 ) specify the formula used by technical investors to calculate their position:

- If $M A\left(w_{S}^{t r}\right)_{t}$ crosses $M A\left(w_{L}^{t r}\right)_{t}$ from below, then the agent opens a long position:

$$
\operatorname{pos}_{t}^{t r}=25 \cdot \mid \Delta \text { incl }_{t}^{t r} \mid
$$

- If $M A\left(w_{S}^{t r}\right)_{t}$ crosses $M A\left(w_{L}^{t r}\right)_{t}$ from above, then the agent opens a short position:

$$
\operatorname{pos}_{t}^{t r}=-25 \cdot\left|\Delta i n c l_{t}^{t r}\right|
$$

where

- 25 is a normalisation factor aimed at having the same order of magnitude in the orders from fundamentalist and technical agents.

- $\Delta i n c l_{t}^{t r}$ is the difference between the slope of the two MA's:

$$
\Delta i n c l_{t}^{t r}=\arctan \left(M A\left(w_{S}^{t r}\right)_{t}-M A\left(w_{S}^{t r}\right)_{t-1}\right)-\arctan \left(M A\left(w_{L}^{t r}\right)_{t}-M A\left(w_{L}^{t r}\right)_{t-1}\right)
$$

Technical investors keep their positions open until they think that the price trend has begun to reverse. In order to detect a trend reversal, the agents use a channel breakout rule: if the current price is the lowest in the last $w_{C}^{t r}$ days, then the technical trader interprets that the price is going down, and any long position should be liquidated; if the current price is the highest in the last $w_{C}^{t r}$ days, then the technical trader interprets that the price is going up, and any short position should be liquidated. 


$$
\begin{aligned}
& \text { If } \operatorname{pos}_{t-1}^{t r}>0 \& P_{t}=\underset{j \in\left[t-w_{C}^{t r}+1, t\right]}{\operatorname{Min}}\left\{P_{j}\right\} \text { then } \operatorname{pos}_{t}^{t r}=0 . \\
& \text { If } \operatorname{pos}_{t-1}^{t r}<0 \& P_{t}=\underset{j \in\left[t-w_{C}^{t r}+1, t\right]}{\operatorname{Max}}\left\{P_{j}\right\} \text { then } \operatorname{pos}_{t}^{t r}=0 .
\end{aligned}
$$

Note that when drawing the minimum and the maximum of the price over a period, a channel appears, which is why the method is called "channel breakout" (Figure 3).

As happens with the fundamentalist investors, when a technical agent has an open position, but the channel breakout conditions is not satisfied, then he simply updates his position keeping the same sign:

$$
\begin{aligned}
& \text { If } \operatorname{pos}_{t-1}^{t r}>0 \text { then } \operatorname{pos}_{t}^{t r}=25 \cdot \mid \Delta \text { incl }_{t}^{t r} \mid \\
& \text { If } \operatorname{pos}_{t-1}^{t r}<0 \text { then } \operatorname{pos}_{t}^{t r}=-25 \cdot\left|\Delta i n c l_{t}^{t r}\right| .
\end{aligned}
$$

Technical investors are heterogeneous in the windows of the moving averages and breakout channel

$$
w_{S}^{t r} \sim U\left(w_{S, \min }^{t r}, w_{S, \max }^{t r}\right), \quad w_{L}^{t r} \sim U\left(w_{L, \min }^{t r}, w_{L, \max }^{t r}\right), \quad w_{C}^{t r} \sim U\left(w_{C, \min }^{t r}, w_{C, \max }^{t r}\right) .
$$

Once set the new position, the agent calculates the order to be sent to the market-maker:

$$
\theta_{t}^{t r}=\operatorname{pos}_{t}^{t r}-\operatorname{pos}_{t-1}^{t r} \text {. }
$$

Figure 4 summarises how the technical strategy works:

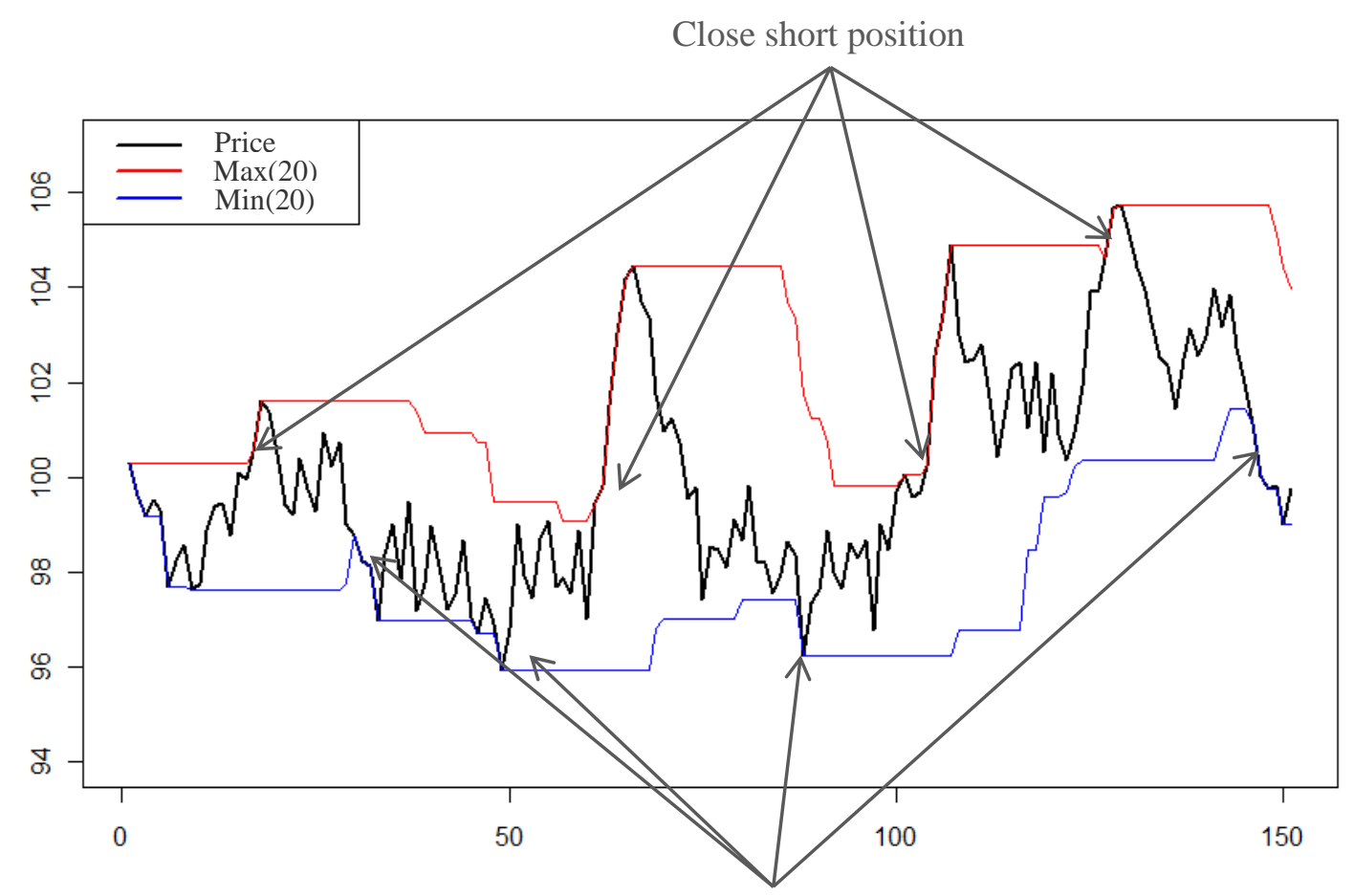

Close long position

Figure 3 - Illustration of the behaviour of the channel used as exit condition 


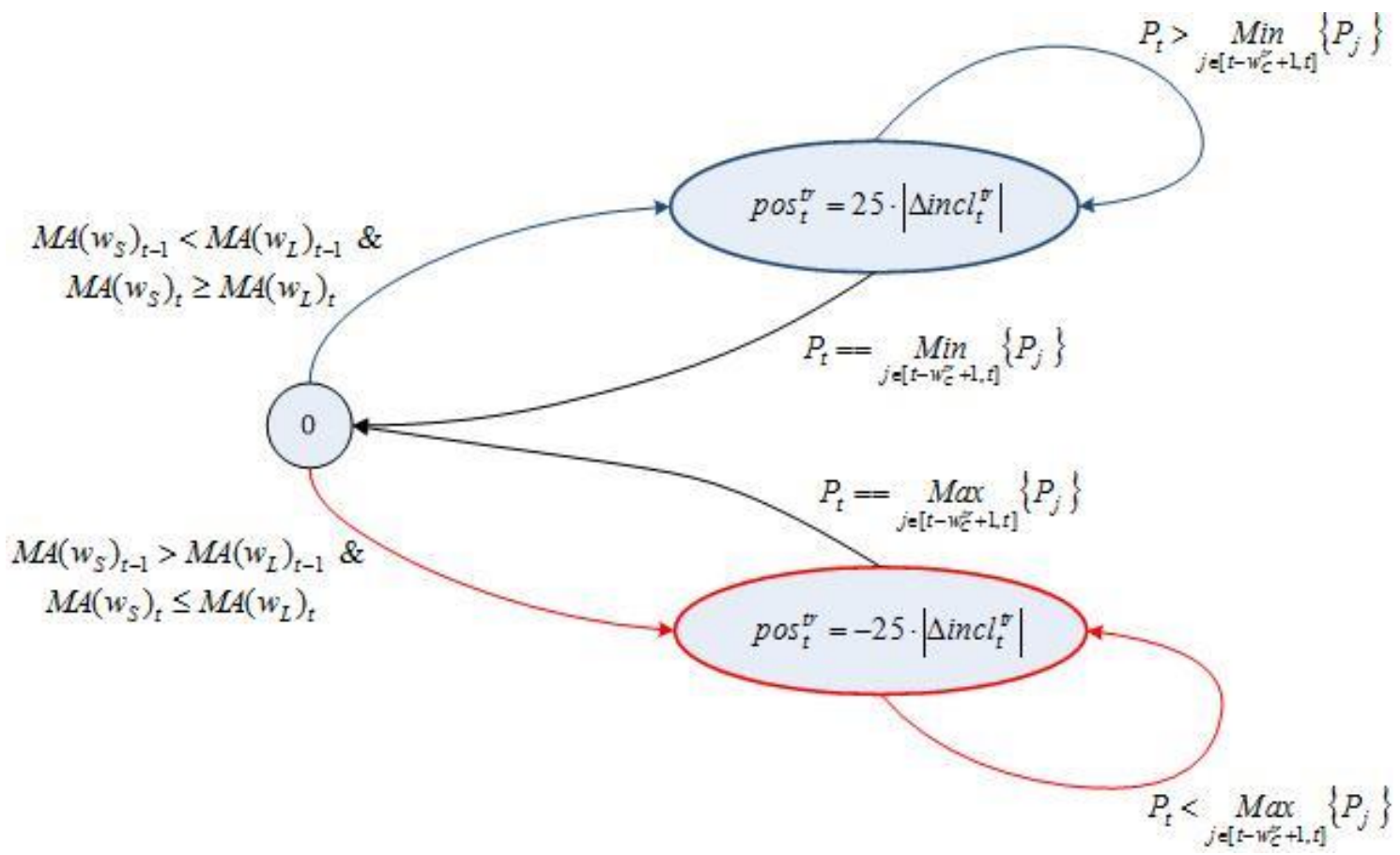

Figure 4 - State diagram of the technical strategy

\subsubsection{Value-at-risk model}

Up to this point, we have assumed that agents exclusively relied on valuation models to determine the number of shares to buy or sell in any given time step. To account for the market risk of the portfolio, we now introduce a risk model based on $\mathrm{VaR}$ position limits. We assume that for a given portfolio and time horizon $\Delta t_{h}=t_{h}-t$ the variation of the portfolio value is distributed normally with mean $\mu=0$ and normalised variance $\sigma_{t}^{2}$. An estimate for the maximum loss of the portfolio value Value ${ }^{P}$ for the confidence level $\alpha$ is

$$
\operatorname{VaR}_{t}=z_{1-\alpha} \cdot \sigma_{t} \cdot \text { Value }_{t}^{P} \cdot \sqrt{\Delta t_{h}},
$$

where $z_{1-\alpha}$ is the percentile of the normal distribution corresponding to a level of confidence equal to $\alpha$.

Let $\theta_{t}$ be the order that an investor wants to issue according to its fundamentalist or technical strategy. Before sending this order to the market maker, the agent calculates the 1-tick VaR of the position it would have in the stock if the order $\theta_{t}$ became effective:

$$
\operatorname{VaR}_{t}=z_{1-\alpha} \cdot \sigma_{t} \cdot\left|\operatorname{pos}_{t-1}+\theta_{t}\right| \cdot P_{t}
$$

In case the VaR of the desired position (equation ( 13 )) does not exceeds the VaR limit LVaR of the agent, the order is sent to the market maker to calculate the new price; otherwise, the agent needs to reduce the order to a level where the VaR of the resulting portfolio is below the limit $(L V a R)$ : 


$$
\operatorname{pos}_{t}^{r e d}=\left(\operatorname{pos}_{t-1}+\theta_{t}\right) \cdot \frac{L V a R}{V a R_{t}} .
$$

Then the order actually sent to the market maker needs to be adjusted:

$$
\theta_{t}^{\text {red }}=\operatorname{pos}_{t}^{\text {red }}-\text { pos }_{t-1} \text {. }
$$

Traders are heterogeneous in ther VaR limit and in the window used to calculate the volatility of the assets:

$$
L V a R \sim U\left(L V a R_{\min }, L V a R_{\max }\right), \quad w^{\sigma} \sim U\left(w_{\min }^{\sigma}, w_{\max }^{\sigma}\right) .
$$

\subsubsection{Measuring financial instability}

The objective of this paper is to analyse the impact of the widespread use of VaR systems on market stability. It is difficult to define what financial stability exactly is, but all the proposed definitions agree that financial stability is linked to the absence of crises, stress or excessive volatility (Gadanecz \& Jayaram, 2008). It is even more difficult to measure financial stability: to this aim, central banks and other regulators use indices that combine simple indicators that provide information not only on financial markets but also on real economy or corporate sector to account for the fact that financial stability is connected to the proper functioning of the macroeconomic environment (Manamperi, 2013). Our model is just a stylised version of a stock market, and so we cannot implement stability indicators pertaining to any sector other than financial markets. Building on the real-world indicators used by regulators in this sector, we will implement the following indicators of financial instability, which essentially measure the intensity of price movements and the fragility of market participants:

- Return volatility: Market volatility, which measures the size of price movements (Gadanecz \& Jayaram, 2008), is the most usual indicator of financial stability (The World Bank, 2013). We define volatility as the standard deviation of the return series of an asset, $r^{i}$, calculated within a window $w$ :

$$
\sigma_{t}^{r_{i}}=\sqrt{\frac{1}{w-1} \cdot \sum_{k=t-w+1}^{t}\left(r_{k}^{i}-\mu_{t}^{r_{i}}\right)^{2}},
$$

where $\mu^{r_{i}}$ is the average of returns $r^{i}$ calculated within the same window $w$.

- Return kurtosis ${ }^{4}$ : Kurtosis of returns is the fourth central moment of the return distribution:

$$
k_{t}^{r_{i}}=\frac{\frac{1}{w} \cdot \sum_{k=t-w+1}^{t}\left(r_{k}^{i}-\mu_{t}^{r_{i}}\right)^{4}}{\left(\sigma_{t}^{r_{i}}\right)^{4}},
$$

where $\mu^{r_{i}}$ is the mean and $\sigma^{r_{i}}$ is the standard deviation of returns $r^{i}$, both calculated within the window $w$. Kurtosis measures the size of the tails of the probability distribution of returns (Tsay, 2005), and so it has been used as an indicator of financial

\footnotetext{
${ }^{4}$ In fact, we implement excess kurtosis, which is equal to $k_{t}^{r_{i}}-3$, where 3 is the kurtosis of a normal distribution.
} 
stability ( (Brunnermeier \& Pedersen, 2009), (Peters, 2014)), since a higher value of kurtosis is a sign of a higher frequency of extreme returns. However, it must be pointed out that kurtosis is quite sensitive to the appearance of outliers because the deviation of each observation with respect to the mean is raised to the fourth power (Rebonato, 2007).

- Hill tail index: Apart from kurtosis, the behaviour of the tails of the return distribution can be described through the tail index. In recent years it has been determined that the complementary cumulative distribution function of returns asymptotically follows a power law distribution (also sometimes called Pareto distribution)

$$
F(x)=P(X>x) \sim x^{-\alpha 5}
$$

and so the descent of the probability density function also follows a power law distribution in the tails with exponent $\alpha+1$ (Cristelli, 2014). The exponent $\alpha$ coincides with the so-called tail index of the return distribution, which measures the order of the largest absolute moment that is finite (for example, the tail index of a normal distribution is $\infty$ because all of its moments are finite, and the greater this index is, the thinner the distribution tails are) (Cont, 2001). The exponent $\alpha$ is usually estimated with the Hill index 6 , which is the maximum-likelihood estimator of the tail index (Einarsson, 2013). So, when the Hill index of the return series takes a low value, it indicates that returns are more likely to take extreme values, what is a sign of heightened instability (Hermsen, 2010).

- Investor strength: Building on the z-score used to measure the fragility of banks (Beck, De Jonghe, \& Schepens, 2011), we define an indicator of investor strength as the ratio between the end-of-simulation accumulated profits and the standard deviation of these final profits. This indicator provides an idea of the consistency of traders' results and so of their stability.

\subsubsection{Parameters}

Table 1 summarises the value of all the model parameters used in the results described next. When choosing these values, we have applied the following criteria:

- For those parameters that are a direct adaptation of real strategy parameters, we have simply chosen realistic values.

- For those parameters not 'observable' in real markets, we have adjusted their value with the aim of obtaining reasonable price dynamics that satisfy as much as possible the stylised facts of stock markets ( (Cont, 2001), (Taylor S. , 2005)). In particular, the model captures the following properties:

${ }^{5}$ The notation $\sim$ is used to describe the asymptotical behaviour of a function (Clegg, 2006):

$$
f(x) \sim g(x) \rightarrow \lim _{x \rightarrow \infty} \frac{f(x)}{g(x)}=1
$$

${ }^{6}$ Let $k$ be the number of observations in the tail of a distribution. If these observations are sorted in descending order, $x_{(1)} \geq x_{(2)} \geq \cdots \geq x_{(k)}$, then the Hill estimator is defined as (Einarsson, 2013):

$$
\hat{\alpha}=\frac{k}{\sum_{i=1}^{k-1}\left(\ln x_{(i)}\right)-(k-1) \ln x_{(k)}}
$$


- Lack of return autocorrelation: The autocorrelation function of the return series obtained from the simulations tend to 0 when the lag increases.

- Fat tails: The distribution of the return series obtained from the model is more leptokurtic than the normal distribution. Returns present excess kurtosis, and their histogram has more mass in the center and the tails than a normal distribution.

- Volatility clustering: The autocorrelation function of volatility -estimated either as the absolute value or the square of returns - remains positive for several lags, and volatility presents long-term memory.

- Correlation between volume and volatility: The correlation between trading volume (calculated as the sum of orders issued by all the agents in absolute value) and volatility is positive.

- Volume autocorrelation: The autocorrelation function of the volume series obtained from simulations remains positive for several lags and decays slowly to 0 , and volume has long-term memory.

Next, we describe in more detail how we have calibrated each parameter ${ }^{7}$ :

- Parameters associated to price formation: The impact of traders in price formation is normalised with the liquidity parameter $\lambda$, so this parameter is linked to the number of agents (the higher the trader population size, the higher the liquidity). Although this parameter has an empirical interpretation, its value is not observable, and it has then been calibrated by looking at the stylised facts replicated by the model.

The random term in price formation (see formula $(1)$ ) is governed by the standard deviation parameter $\sigma_{P}$, whose value has been set to obtain an overall price volatility value in line with empirical daily volatility of S\&P500 (assuming here that one time step is equivalent to one trading day).

- Parameters associated to fundamental value formation: The fundamental value process depends on the standard deviation term $\sigma_{V}$. This has been calibrated based on the stylised facts replicated by the model.

- Parameters associated to the fundamentalist strategy: Although we do not have empirical evidence on which thresholds are used by fundamentalist traders, we have used plausible values for the mispricing level required to enter and exit a position $\left(T^{f}\right.$, $\tau^{f}$ ), and we have fine-tuned these values - together with the unobservable parameter $v^{f}$ - by looking at the stylised facts replicated by the model.

- Parameters associated to the technical strategy: To implement the technical trading strategy, we have built on techniques widely used in real markets, and so when it came to setting the values of the different windows we turned to the practitioner literature. The windows for the short- and long-term moving averages $\left(w_{S}^{t r}, w_{L}^{t r}\right)$ move around 10 and 40 as these are the values usually employed by real technical investors (Kestner, 2003); the window for the exit channel moves around 20 as this is the typical period (Milton, 2016).

\footnotetext{
${ }^{7}$ The calibration has been done before introducing the VaR model, to have a valid testbed where to study the effect of risk management practices.
} 


\begin{tabular}{|c|c|c|}
\hline Parameter & Value & Parameter description \\
\hline$N_{\text {ticks }}$ & 4000 & Number of ticks (or time steps) of each run \\
\hline$\lambda$ & 400 & Liquidity \\
\hline$P_{0}$ & 100 & Initial price \\
\hline$\sigma_{P}$ & 0.4 & Standard deviation for random term in price formation \\
\hline$N_{F U N D}$ & 200 & Number of fundamentalist traders \\
\hline$N_{\text {TREND }}$ & 200 & Number of technical traders \\
\hline$\sigma_{V}$ & 0.25 & $\begin{array}{l}\text { Standard deviation for random term in fundamental value } \\
\text { formation }\end{array}$ \\
\hline$\left[v_{\min }^{f}, v_{\max }^{f}\right]$ & {$[-8,8]$} & $\begin{array}{l}\text { Boundaries of the uniform distribution that sets the } \\
\text { difference between the fundamental value and the value } \\
\text { perceived by each fundamentalist trader }\end{array}$ \\
\hline$\left[T_{\min }^{f}, T_{\max }^{f}\right]$ & {$[2,5]$} & $\begin{array}{l}\text { Boundaries of the uniform distribution that sets the entry } \\
\text { thresholds of fundamentalist traders }\end{array}$ \\
\hline$\left[\tau_{\min }^{f}, \tau_{\max }^{f}\right]$ & {$[-0.5,1]$} & $\begin{array}{l}\text { Boundaries of the uniform distribution that sets the exit } \\
\text { thresholds of fundamentalist traders }\end{array}$ \\
\hline$\left[w_{S, \min }^{t r}, w_{S, \max }^{t r}\right]$ & {$[5,15]$} & $\begin{array}{l}\text { Boundaries of the uniform distribution that sets the } \\
\text { window of short-term moving average used by technical } \\
\text { traders }\end{array}$ \\
\hline$\left[w_{L, \min }^{t r}, w_{L, \max }^{t r}\right]$ & {$[35,50]$} & $\begin{array}{l}\text { Boundaries of the uniform distribution that sets the } \\
\text { window of long-term moving average used by technical } \\
\text { traders }\end{array}$ \\
\hline$\left[w_{C, \min }^{t r}, w_{C, \max }^{t r}\right]$ & {$[5,30]$} & $\begin{array}{l}\text { Boundaries of the uniform distribution that sets the } \\
\text { window of exit channel used by technical traders }\end{array}$ \\
\hline$\alpha$ & $99 \%$ & Confidence level \\
\hline$\left[L V a R_{\min }, L V a R_{\max }\right]$ & Variable & $\begin{array}{l}\text { Boundaries of the uniform distribution that sets the } \mathrm{VaR} \\
\text { limit of each agent }\end{array}$ \\
\hline$\left[w_{\min }^{\sigma}, w_{\max }^{\sigma}\right]$ & Variable & $\begin{array}{l}\text { Boundaries of the uniform distribution that sets the } \\
\text { window used to calculate the stock volatility }\end{array}$ \\
\hline
\end{tabular}

Table 1 - Table of parameters used in the simulations 


\section{Model results}

In this section we will study how the use of VaR position limits impacts price dynamics and market stability, and will analyse the effect of the different parameters of the VaR model. In all the experiments, simulations have a duration of 4000 time steps (in order to calibrate variables such as price volatility we assume that each time step is equivalent to 1 day, and so each run has an equivalent duration of 16 years). Ech experiment consists of 50 runs and uses the parameters listed in Table 1. We are using identical random number sequences across the different experiments so that the results become comparable.

\subsection{Effect of using VaR systems}

We study next the effect of using $\mathrm{VaR}$-based position limits in the instability indicators described in section 2.2.4. We consider a one-asset market where the proportion of traders both fundamentalist and technical investors - that manage their risk with VaR limits rises across experiments from $0 \%$ to $100 \%$. That is, in the first experiment no agent uses VaR, whereas in the last experiment all agents are using VaR. We assume that all traders are homogeneous in their VaR limit and volatility window:

$$
\begin{gathered}
L V a R=40 \\
w^{\sigma}=20
\end{gathered}
$$

Figure 5 shows the evolution of the different instability indicators ${ }^{8}$ when the percentage of traders using a $\mathrm{VaR}$ system increases from $0 \%$ to $100 \%$. The four indicators show that the market becomes more unstable when most traders manage their risk with VaR limits: the volatility of returns heightens, the kurtosis of returns rises and their Hill tail index goes down which indicates that extreme returns are more frequent -, and the index of trader strength also worsens - because the dispersion of agent profits increases. When a high percentage of traders are using VaR limits, the average market instability increases because of the emergence in some runs of a particular price dynamics which we have called 'VaR cycles'. In fact, the outliers observed in Figure 5 are realised in those runs where VaR cycles are specially remarkable. Let's have a look at a particular simulation to describe in detail the functioning of such cycles.

\footnotetext{
8 The volatility/kurtosis boxplots show the mean of the return volatility/kurtosis entire time series calculated over a rolling window of 20 time steps - obtained for each of the 50 runs.

The line plot for the strength index shows the ratio of the mean of the end-of-simulation wealth across the 50 runs divided by its standard deviation.
} 


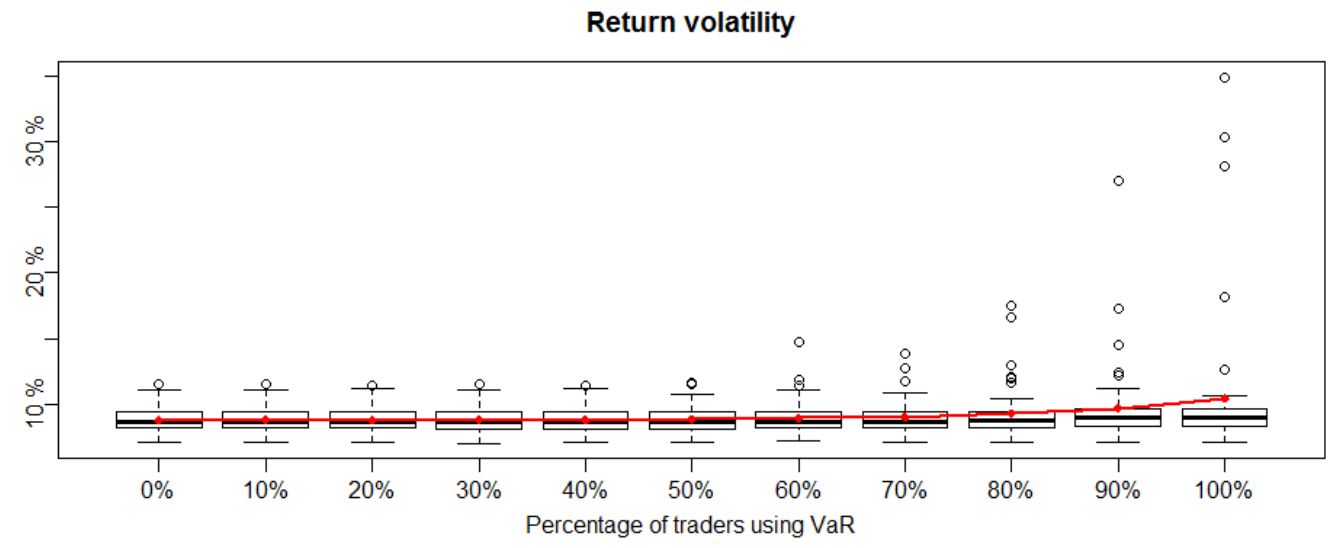

Return kurtosis

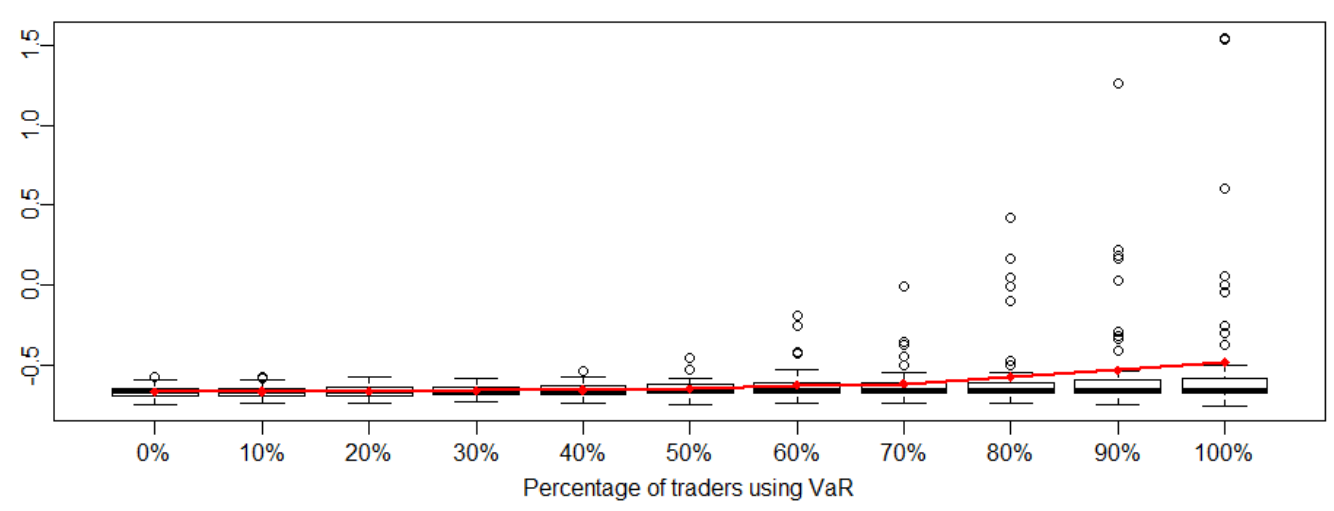

Hill index

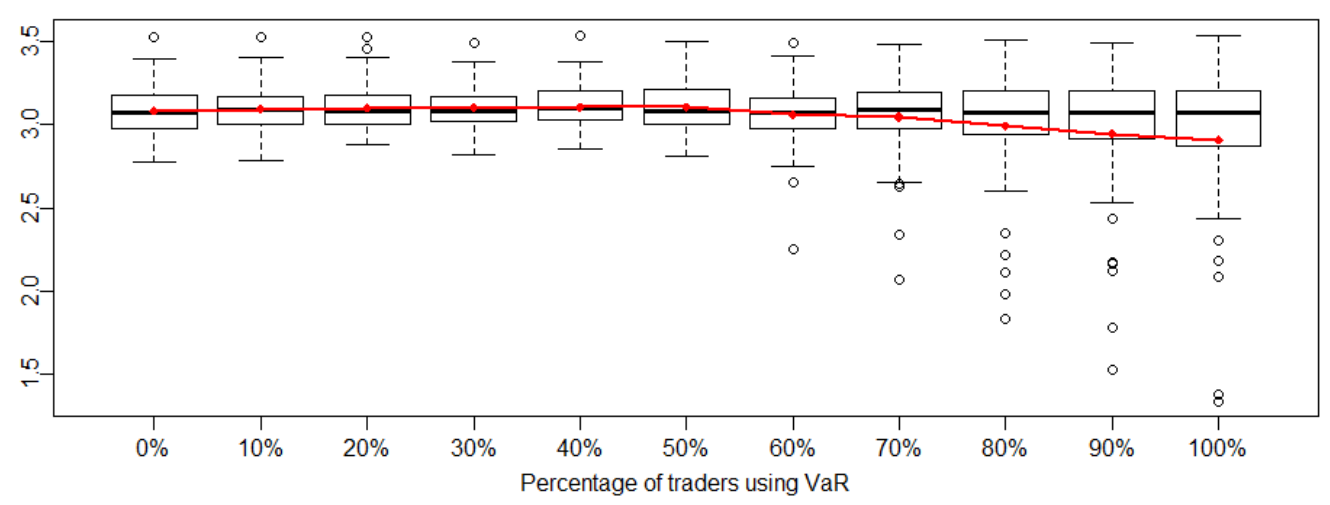

Strength index

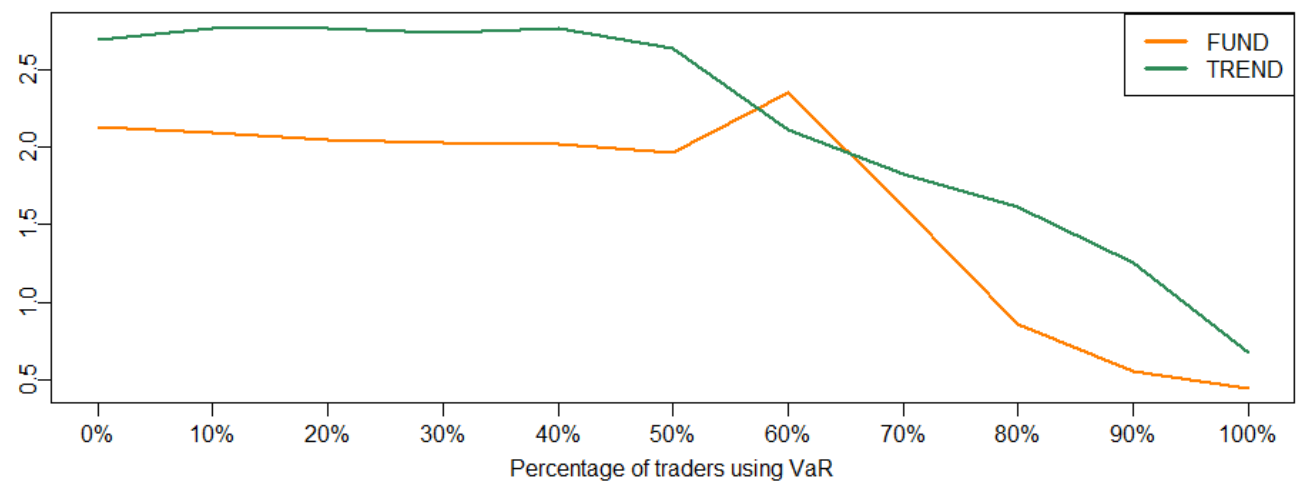

Figure 5 - Evolution of instability indicators when the percentage of agents using VaR increases from $0 \%$ to $100 \%$. From top to bottom: return volatility, return kurtosis, return Hill tail index, and agent strength index. 


\section{Description of a VaR cycle}

Figure 6 compares the price time series obtained in a particular simulation when (1) no agent uses VaR limits (in black), and (2) when all the agents use a VaR model with a limit $L V a R=40$ and a volatility window $w^{\sigma}=20$ (in red). A different behaviour can be appreciated from $t=$ 2900 onwards. For better clarity, a zoom of the price series for $t=3200 . .3500$ is provided in Figure 7 to appreciate the differences in price dynamics.

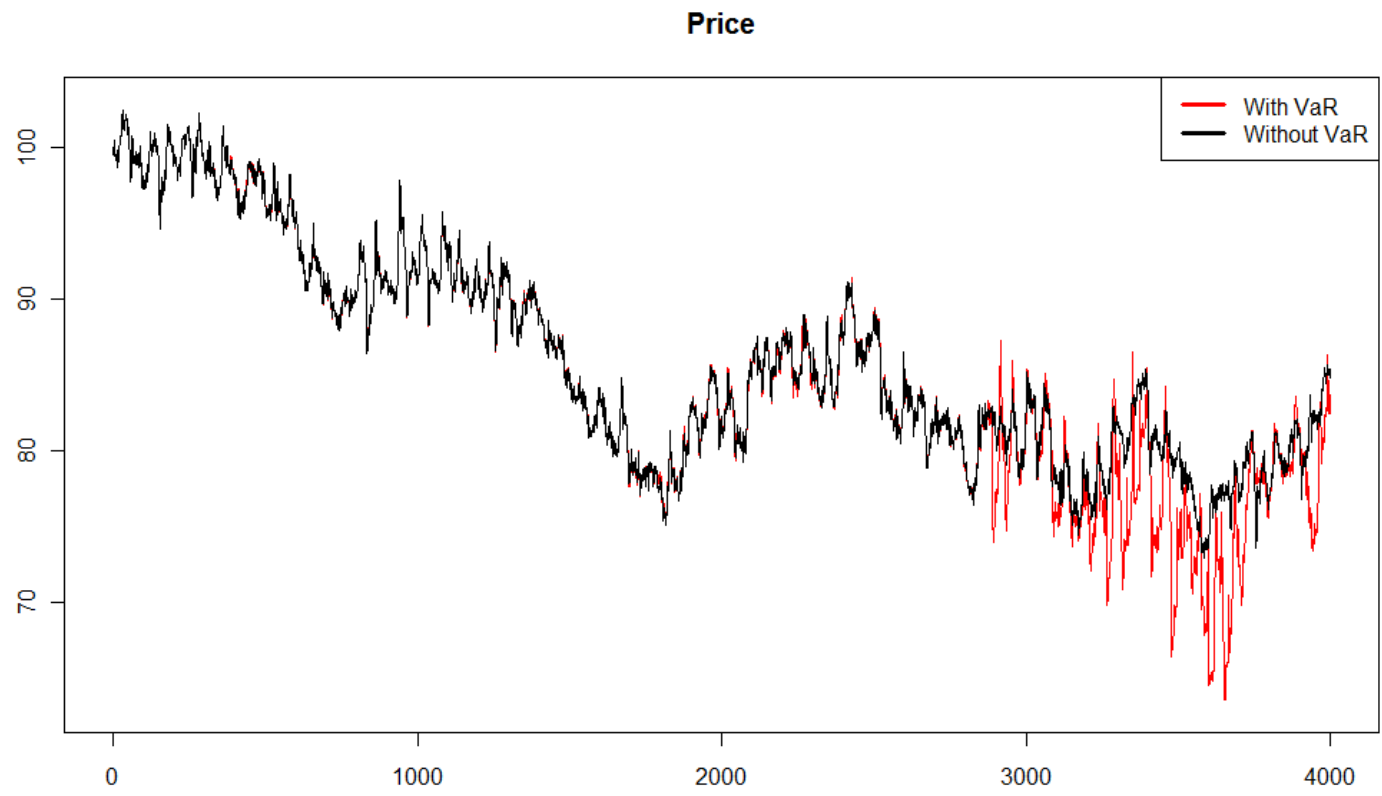

Figure 6 - Comparison of price time series for a particular run when no agent uses VaR (in black), and when all the agents use VaR (in red)

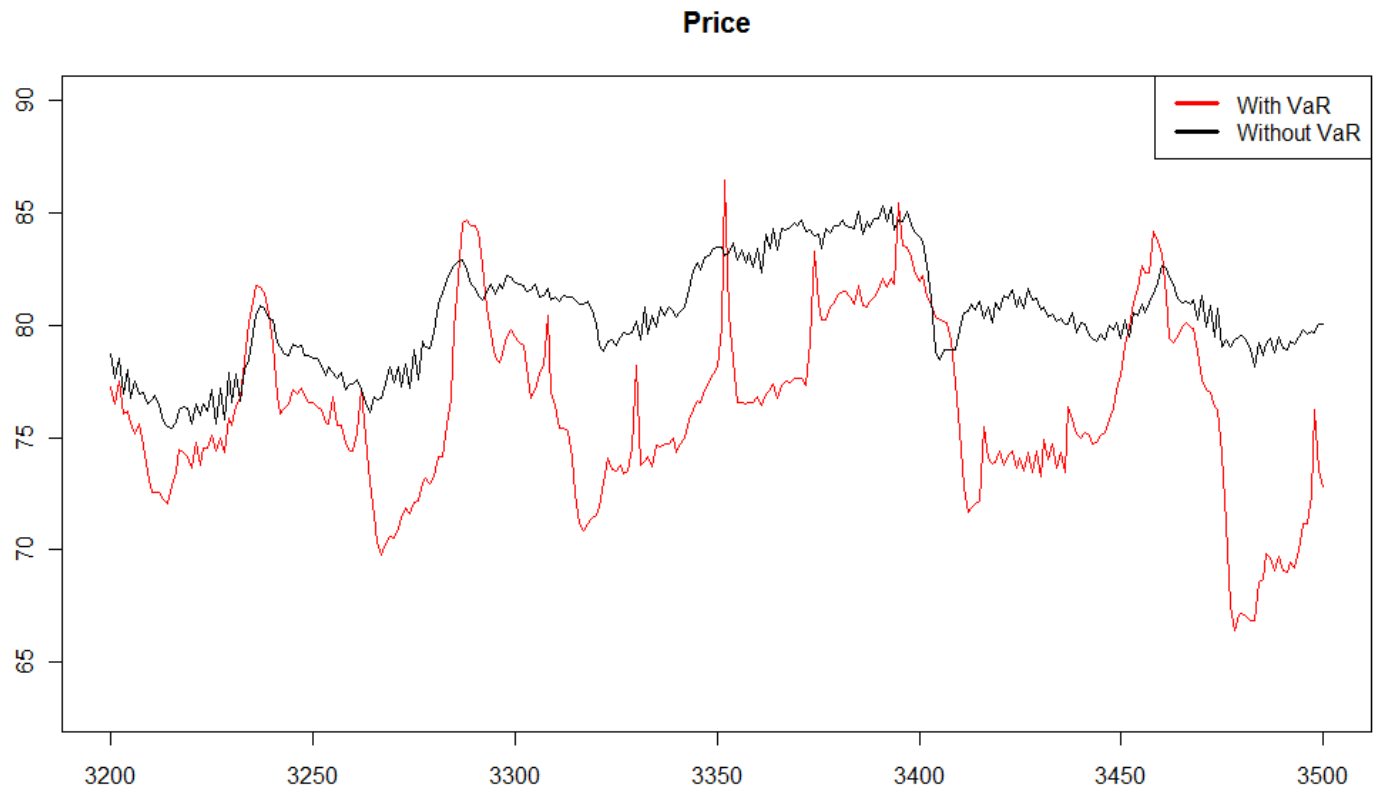

Figure 7 - Zoom in $t=3200-3500$ of the comparison of price time series for a particular run when no agent uses VaR (in black), and when all the agents use VaR (in red) 
Price behaviour from $t=2900$ on is due to the trader action after reaching their VaR limit. Figure 8 exhibits the VaR of agents' portfolio, averaged over fundamentalist and technical investors. This VaR is calculated with the positions that agents would accumulate if they were allowed in the current time step to buy or sell the amount dictated by their trading strategy. From $t=2900$ onwards, agents' VaR exceeds their LVaR limit - represented with a horizontal, red line -, and so traders are forced to forget about their 'desired' orders and need to reduce their portfolio to keep their VaR below the limit.

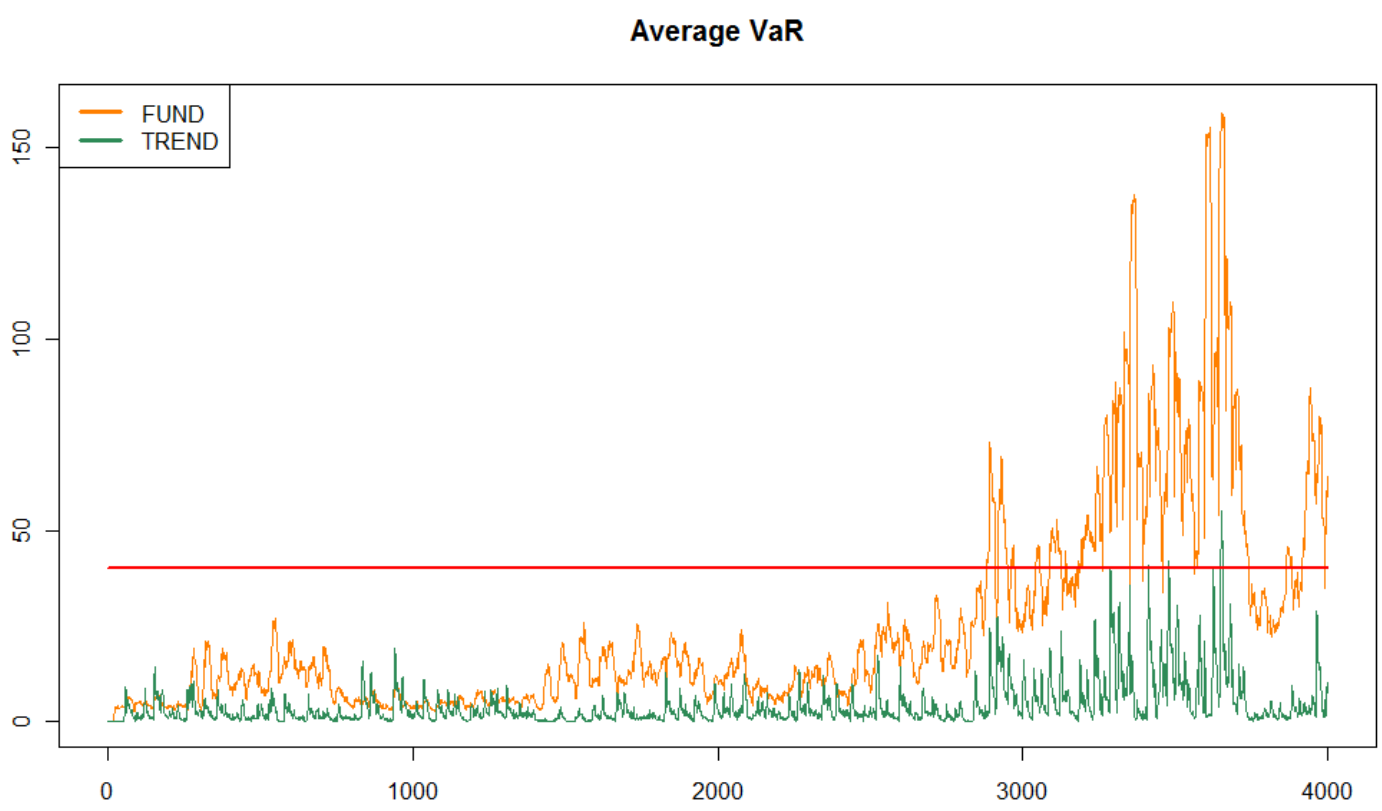

Figure 8 - VaR time series of agents' portfolio for a particular run, averaged over fundamentalist (in orange) and technical (in green) traders

Note that major price movements are caused by agents reducing their portfolio, but this does not mean that price exhibits $\mathrm{VaR}$ cycles everytime that an agent is forced to liquidate part of its positions. In fact, there are some fundamentalist agents that touch their VaR limit before $t=$ 2900 and are thus forced to reduce their positions, but the average VaR over all the fundamentalist population lies below the limit as seen in Figure 8. As these reductions are small compared to the total trading volume, their impact on price is minor. However, when most agents accumulate substantial positions and their portfolio $\mathrm{VaR}$ is close to the limit, any small upsurge in volatility can make VaR rise above the limit and force traders to liquidate positions. When a number of traders must reduce their portfolio at the same time, these reductions have a noticeable impact on the price and, in turn, on volatility.

Figure 9 shows the time series of price, return volatility and 'forced' portfolio reductions of fundamentalist (in orange) and technical traders (in green). When these reductions are different from zero, it indicates that at least some agents not only cannot send to the market their 'desired' order - that is, the order dictated by their trading strategy -, but are forced to partially liquidate their positions to reduce their $\mathrm{VaR}$ to an acceptable level. It can be observed that within the interval $t=3200-3500$ - zoomed in Figure 10 -, the first substantial portfolio reductions around $t=3260$ push the price down and the volatility up, but this process keeps along for a while because the increase in volatility rises again the VaR of agents, which must reduce again their positions, and so on. 
Price

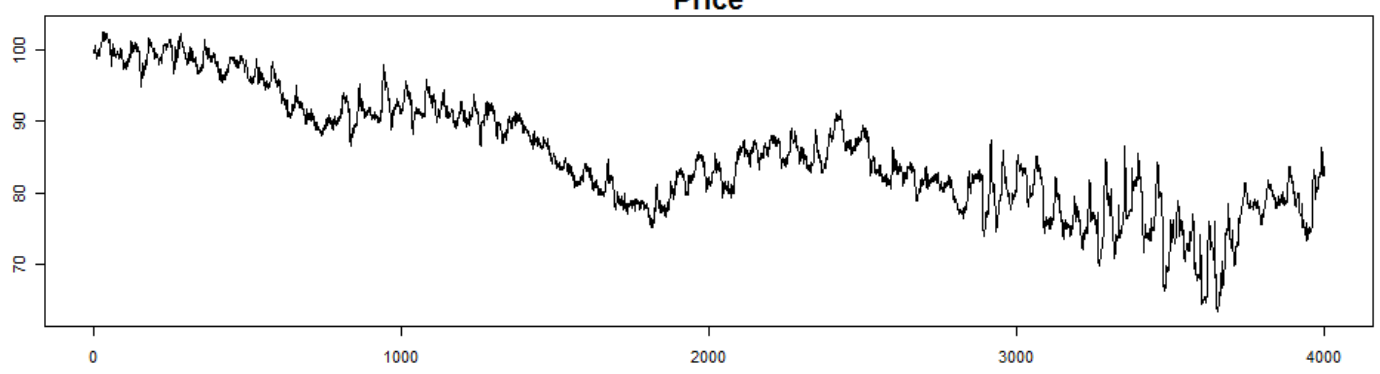

Annualised volatility

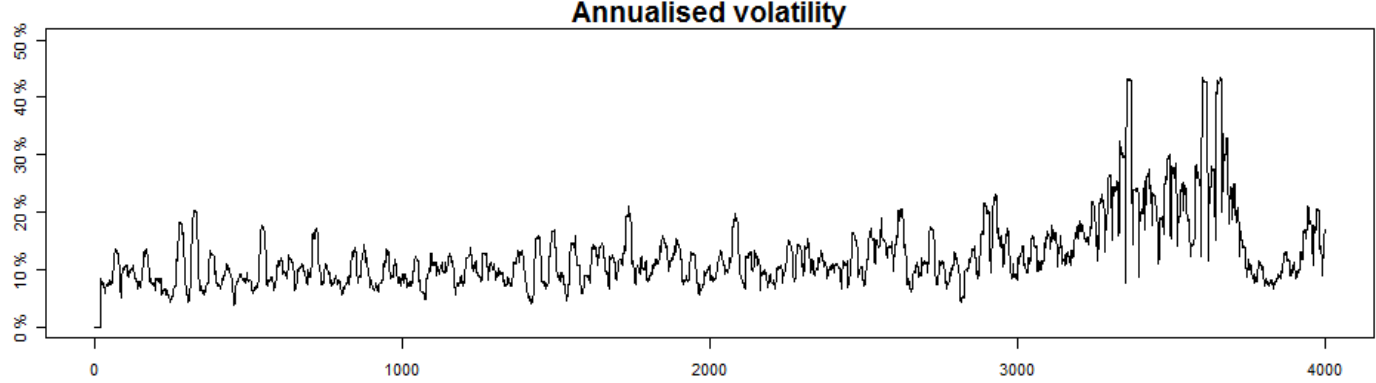

VaR-induced position reductions

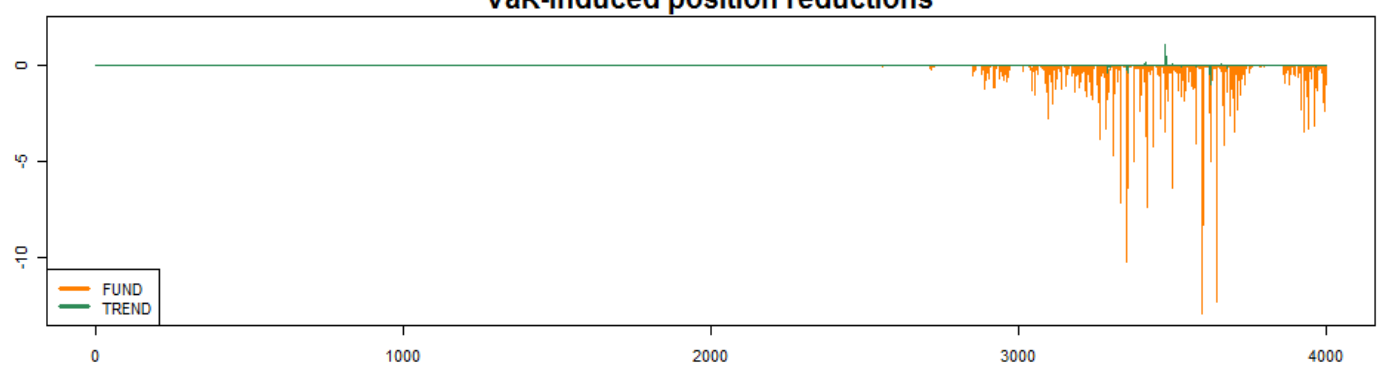

Figure 9 - Time series of prices, annualised return volatility and portfolio reductions of fundamentalist (in orange) and technical traders (in green) for a particular run

When agents have sufficiently reduced their portfolio, their orders get smaller and the price decline slows down. Volatility remains high while the window over which it is calculated still includes the first major movements in price. Nevertheless, when time goes by and volatility decreases, traders start trading again as usual. If there is some coordination between investors and they simultaneously buy or sell, then the price movements can be substantial enough to rise again volatility and cause agents to reach their VaR limit. The 'VaR cycle' may thus repeat once more (see for example the portfolio reductions around $t=3310,3330,3350$, etc. which plunge the price and raise the volatility). 

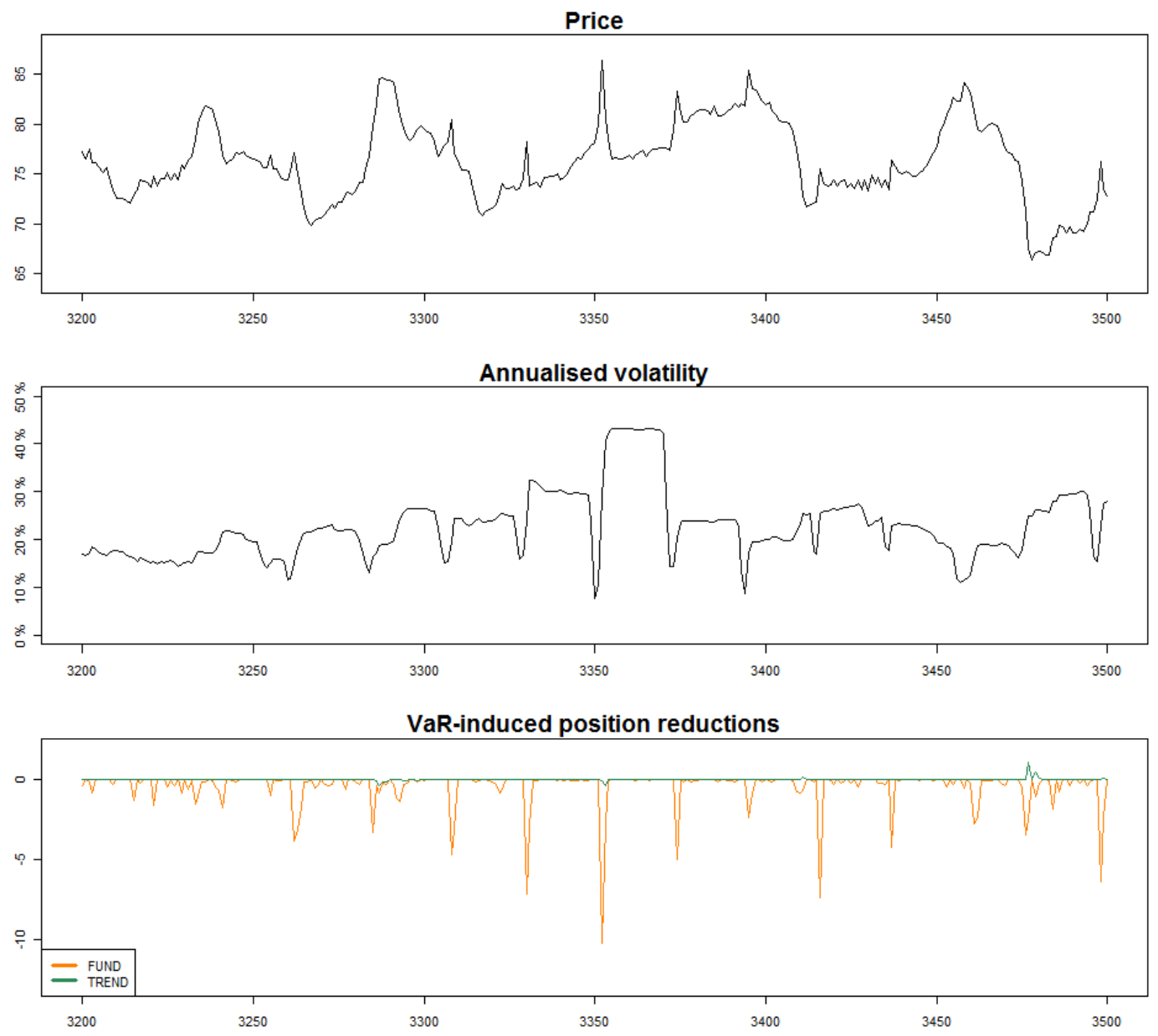

Figure 10 - Zoom in $t=3200-3500$ of the time series of prices, annualised return volatility and portfolio reductions of fundamentalist (in orange) and technical traders (in green) for a particular run

In the experiments just described we have seen that the higher the proportion of agents using $\mathrm{VaR}$, the higher the possibility that VaR cycles emerge, that is, episodes where the reduction of positions by some traders rises the volatility enough to force other agents to sell off part of their holdings to reduce their exposure, thereby increasing volatility again and reinforcing the instabilisation spiral. Given that the market is more likely to suffer instability bouts when all of the agents use a VaR system, our experiments suggest that, at the global level, it would be more beneficial that not all of the investors control their positions with a VaR-based limit; they could use other types of risk management models, or at least they could use more flexible limits that do not force them to reduce their portfolio automatically when exceeding their risk threshold.

The appearance of VaR cycles largely depends on the value of the parameters used by traders in their VaR model. For this reason, we will study next the effect of the volatility window and the $\mathrm{VaR}$ limit in the potential market instabilisation.

\subsection{Effect of volatility window}

We will explore next the impact of a varying value of the window used to calculate volatility in the VaR model, $w^{\sigma}$. This analysis is relevant to certain discussions about the effects of VaR systems: the potentially destabilising effect of VaR models puts into question the adequacy of the capital requirements set out in the Basel Accords, which may exacerbate the episodes of 
financial instability that they are precisely intended to prevent (Persaud, 2000). However, Jorion (2002) rebuts this argument, and one of his main points focuses on the volatility window: the Basel Accords stipulate that the observation period for historical data should be at least one year, and this highly reduces the sensitivity of VaR to daily price movements. Our analysis contributes to this debate by analysing the smoothing effect of high values of the volatility window.

We consider a one-asset market where all investors manage their risk with VaR. They are heterogeneous in their VaR limit, which takes values between 30 and 50, and use the same window to calculate the asset volatility. All parameters remain constant across the experiments except for the volatility, which increases from $w^{\sigma}=5$ in the first experiment to $w^{\sigma}=50$ in the last experiment:

$$
\begin{aligned}
& \operatorname{LVaR} \sim U(30,50) \\
& w^{\sigma}=5,8,11, \ldots, 50
\end{aligned}
$$

Figure 11 summarises the evolution of the different instability indicators when the volatility window increases from $w^{\sigma}=5$ to $w^{\sigma}=50$. The four indicators show that the market is clearly more prone to turmoil episodes when the volatility window takes low values ${ }^{9}$, and the effect of this parameter becomes less noticeable when the volatility window is higher than 23, approximately. When volatility is calculated using a small window, that is, considering just a few observations, each of these observations has a great weight in the outcome, and volatility turns out to be very sensitive to recent price movements. So when the volatility window is small, VaR can significantly increase from one tick to the next, whereas when volatility is calculated with a higher window, a much sharper price variation is required for volatility to notice it.

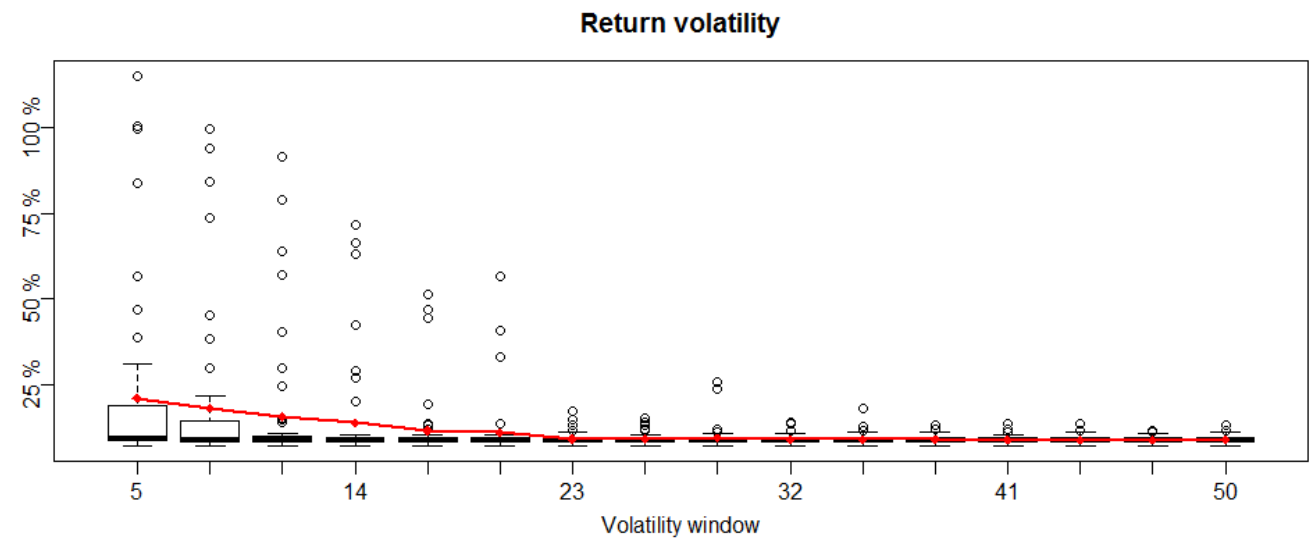

\footnotetext{
${ }^{9}$ Kurtosis shows a somewhat different pattern: it takes more extreme values when volatility window lies between 11 and 20 days, rather than in the first experiments where volatility window takes smaller values. This is curiously due to the minor frequency of VaR cycles: there are still periods of instability, but they are a bit less frequent. As kurtosis is very sensitive to the presence of outliers (see section 2.2.4), it can take higher values when there are bouts of instability of the same magnitude than in the first experiments, but they occur less often.
} 

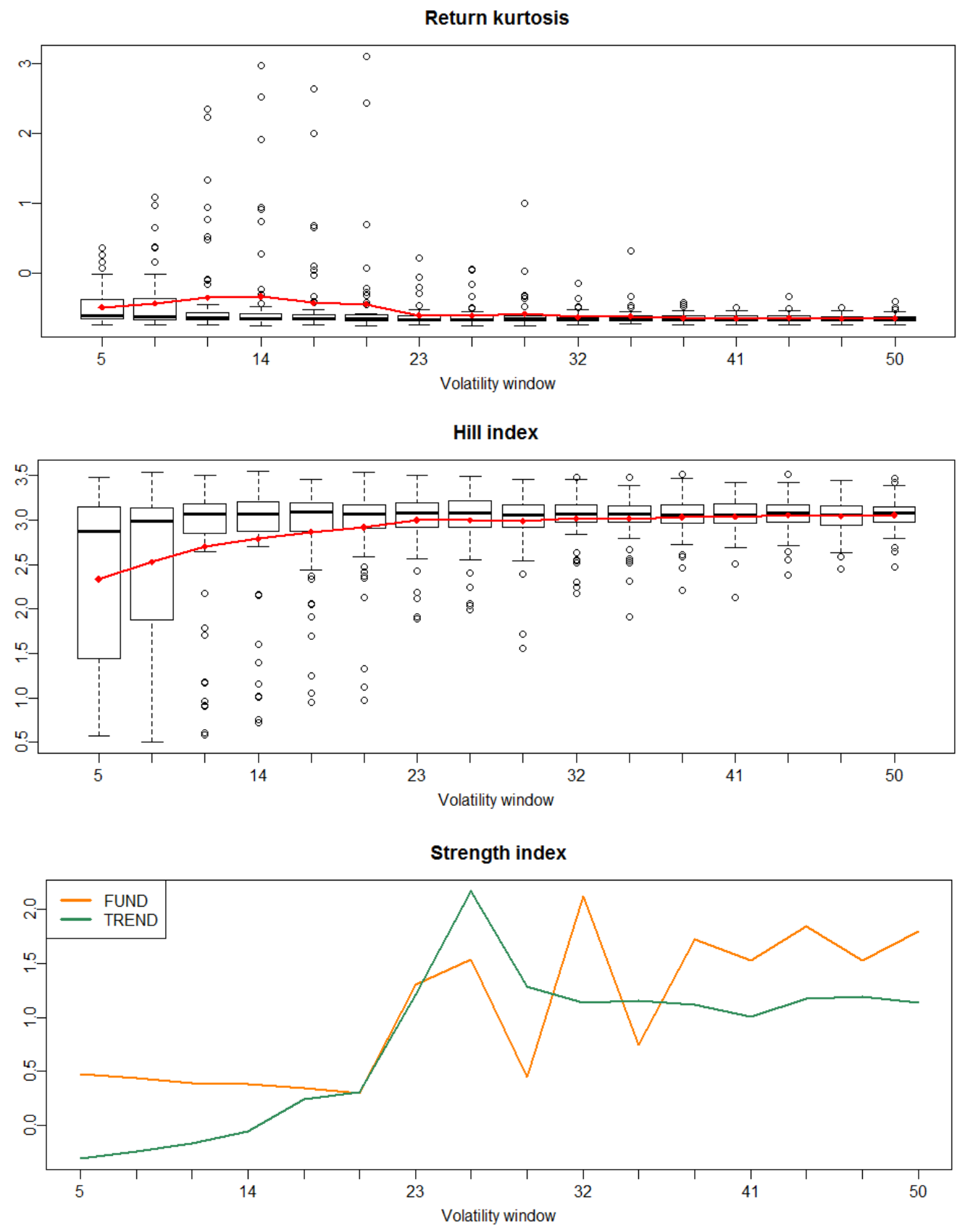

Figure 11 - Evolution of instability indicators when the volatility window increases from 5 to 50 . From top to bottom: return volatility, return kurtosis, return Hill tail index, and agent strength index.

These experiments show that using a medium- or long-term window to calculate volatility highly reduces the appearance of $\mathrm{VaR}$ cycles because volatility becomes less sensitive to price movements ${ }^{10}$. In fact, this sensitivity clearly moderates when the volatility window is beyond 23 days or, to put it another way, when volatility is calculated over a horizon of one month or longer. In connection to the debate about the role of the Basel Accords in exacerbating instability episodes, our results indicate that Jorion (2002) is right in noting that capital

\footnotetext{
${ }^{10}$ This result is in agreement with (Aymanns, Caccioli, Farmer, \& Tan, 2016), where the authors observe in quite a different model from ours that using a longer time horizon for computing volatility increases the stability of the financial system.
} 
requirements do not contribute to increasing market instability because they are based on at least one year of historical data, and so volatility reacts slowly to market movements.

\subsection{Effect of VaR limit}

We will explore now the impact of a varying value of the position limit LVaR used by the agents to control the risk of their portfolio. We consider a one-asset market where all investors manage their risk with VaR. They are heterogeneous in their volatility window, which takes values between 10 and 30, and use the same VaR limit. All parameters remain constant across the experiments except for the $\mathrm{VaR}$ limit, which increases from $L V a R=5$ in the first experiment to $L V a R=65$ in the last experiment:

$$
\begin{aligned}
L V a R & =5,8,11, \ldots, 65 \\
w^{\sigma} & \sim U(10,30)
\end{aligned}
$$

Figure 11 summarises the evolution of the different instability indicators when the VaR limit increases from $L V a R=5$ to $L V a R=65$. The four indicators show that the market is more unstable when the VaR limit takes intermediate values (around 11-26), because VaR cycles are then more likely to emerge. On the one hand, if the VaR limit takes a low value, this considerably constrains the positions that agents can take, because the VaR of their portfolio is proportional to the asset positions. So, even though they reach their limit more frequently and are forced to reduce their portfolio, they cannot send large orders to the market because their positions are not huge, and VaR-caused reductions have a smaller effect in market dynamics. On the other hand, if the VaR limit takes a high value, then agents are less likely to reach their limit, and so price dynamics do not differ much from the case in which agents do not manage their risk (in fact, a scenario with a high enough VaR limit is equivalent to a model without $\mathrm{VaR})$.

Although the mean of the different instability indicators over the 50 runs decreases when agents use a VaR limit above $L V a R=26$, it can be observed that instability is still important for higher values of $L V a R$ in a handful of runs (see the outliers of boxplots in Figure 12). In these runs market dynamics still exhibit episodes of VaR cycles, but their frequency and/or duration diminishes as VaR limit increases (see the lower number and values of outliers in Figure 12).

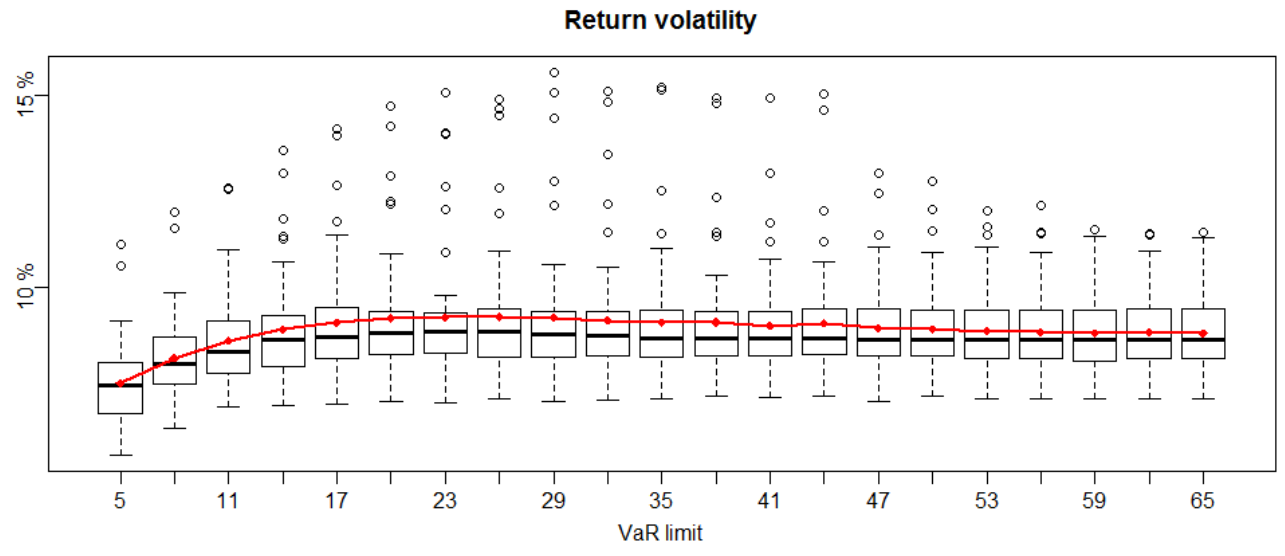



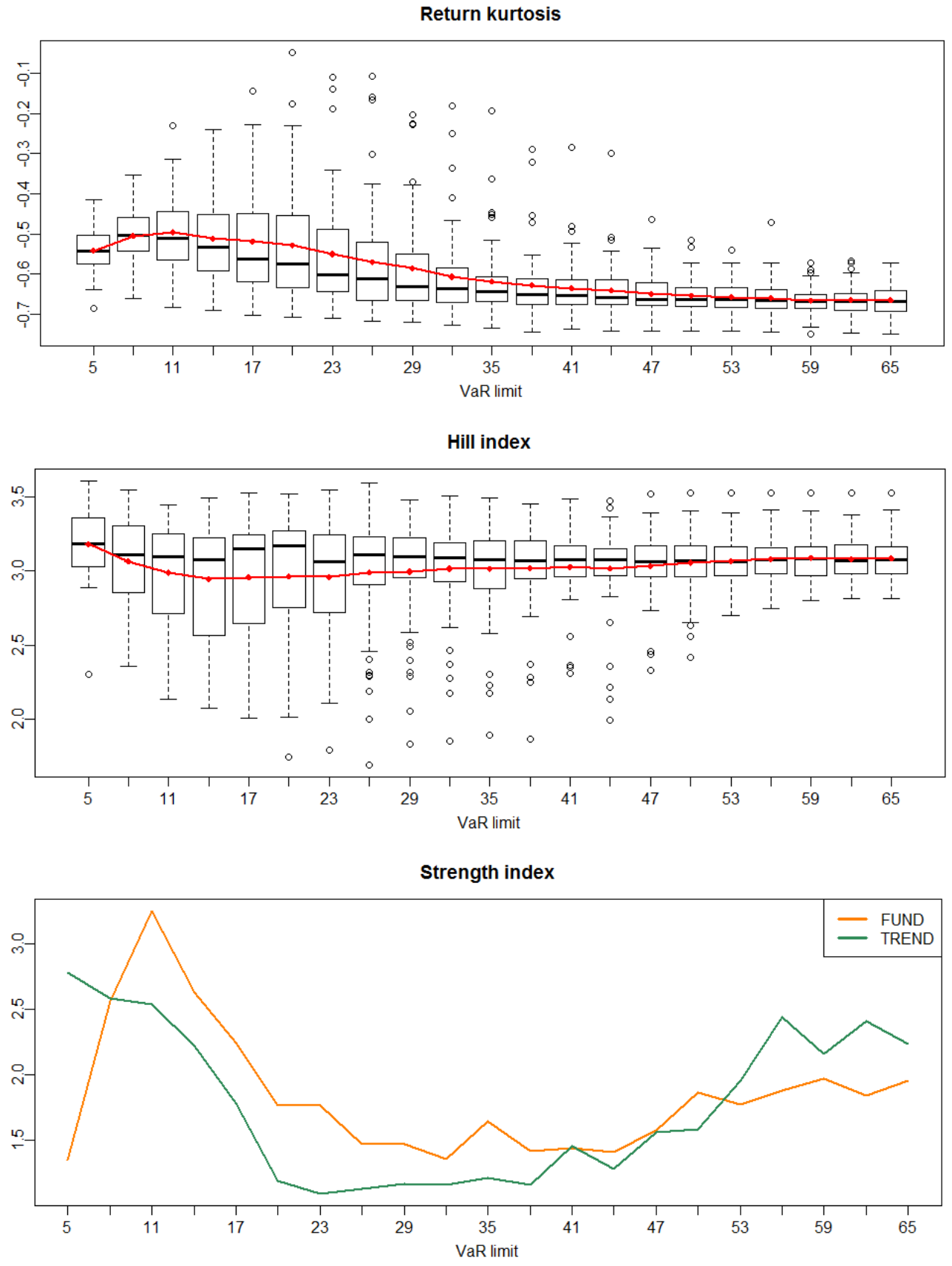

Figure 12 - Evolution of instability indicators when the VaR limit increases from 5 to 65 . From top to bottom: return volatility, return kurtosis, return Hill tail index, and agent strength index.

The behavior of the various indicators across the different experiments leads us to conclude that the market is particularly stable when the limits are either very restrictive or very loose. It is for intermediate values of the VaR that prices show the most interesting dynamics, with the appearance of $\mathrm{VaR}$ cycles when the risk-driven portfolio reductions have a noticeable effect on prices and volatility. We note that there is no need to consider unrealistic values of the VaR limit for instability episodes to appear: $\mathrm{VaR}$ cycles are most likely to appear for $L V a R=11-44$, which correspond approximately to $11 \%-45 \%$ of the average value of traders' portfolio, and in real markets it is quite probable that a financial institution facing losses of this magnitude liquidates some positions to prevent that losses heighten. 


\subsection{Effect of variable VaR limits}

So far we have assumed that VaR limits are constant along time. However, real-world financial institutions adjust these limits based on their risk and return (Saita, 2007). As Jorion (2001) indicates, in times of heightened volatility it is sensible to reduce the maximum VaR threshold. Nonetheless, the adjustment of risk limits can exacerbate the potentially destabilising effect of $\mathrm{VaR}$ systems since in moments of financial turmoil the reduction of VaR limits adds up to the increase of portfolio VaR and both mechanisms urge traders to further reduce their positions.

To study the extent to which the dynamic adjustment of VaR limits contributes to market instability, we next consider a variation of our model where traders update their VaR limit as a function of market volatility. When current volatility $\sigma_{t}$ is greater than the historical volatility $\overline{\sigma_{t}}$ (calculated as the average volatility over the last 200 ticks), the agents warily reduce their $\mathrm{VaR}$ limit as they interpret the market to be more unstable; when current volatility lies under historical volatility, then agents judge the market to be safer and increase their VaR limit:

$$
L V a R_{t}=L V a R_{0} \cdot \frac{\overline{\sigma_{t}}}{\sigma_{t}} .
$$

To study the effect of variable VaR limits, we repeat the experiments in section 3.3, but implementing variable VaR limits: investors are heterogeneous in their volatility window, and have the same $\mathrm{VaR}$ limit. All parameters remain constant across the experiments except for the initial VaR limit, which increases from $L V a R_{0}=5$ to $L V a R_{0}=65$ :

$$
\begin{gathered}
L V a R_{0}=5,8,11, \ldots, 65 \\
w^{\sigma} \sim U(10,30)
\end{gathered}
$$

Traders adjust their VaR limit based on market volatility during the course of simulations.

Figure 13 summarises the evolution of the different instability indicators when the initial VaR limit increases from $L V a R_{0}=5$ to $L V a R_{0}=65$. These experiments reassert the results obtained for constant VaR limits in section 3.3, that is, VaR cycles appear more frequently when the initial VaR limit takes intermediate values (reaching the maximum instability levels around $L V a R_{0}=8-11$ ). When $L V a R_{0}$ takes a very small value, even though traders adjust their VaR limit along simulations, they have no room to accumulate large positions because their VaR easily gets above the limit and are forced to partially liquidate their portfolio; when $L V a R_{0}$ takes a high value, then it is less probable that agents reach their limit and market becomes more stable, though VaR cycles still appear in a significant number of runs (see the number of ouliers in the boxplots, much higher than for constant VaR limit in Figure 12).

For the sake of comparability, the graphics in Figure 13 not only show the average of the different instability indicators across the experiments for variable VaR limits - in red -, but also the average across the experiments for constant VaR limits - in green - (displayed in section 3.3). It can be observed that instability is higher when VaR limits are variable. 


\section{Return volatility}

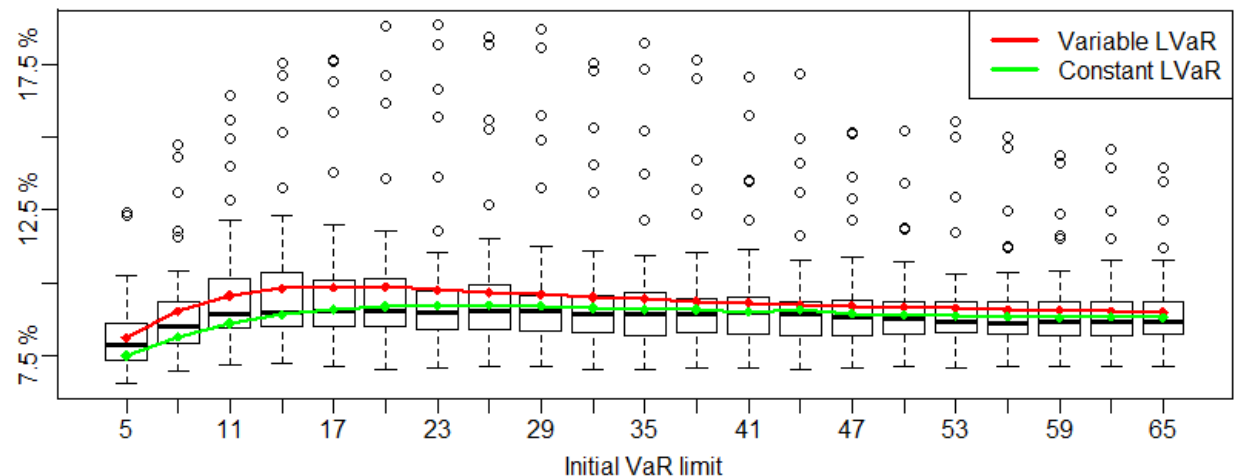

Return kurtosis

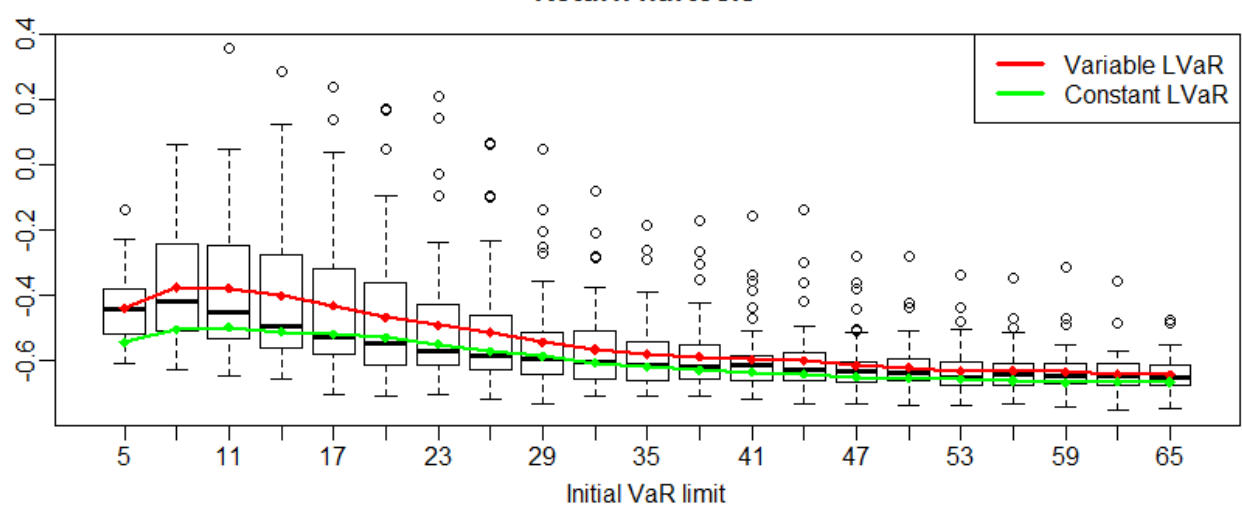

Hill index

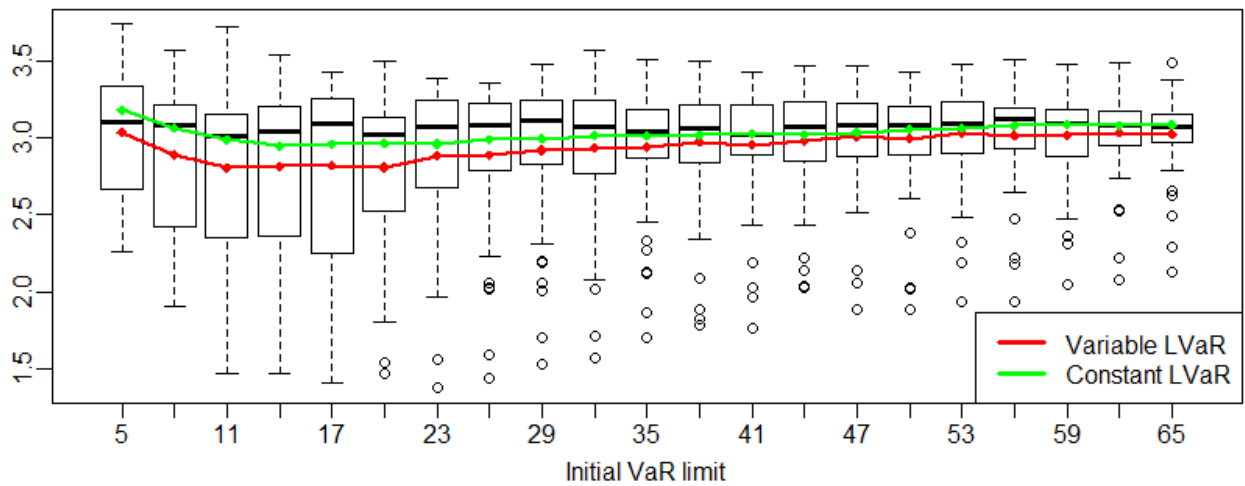

Strength index

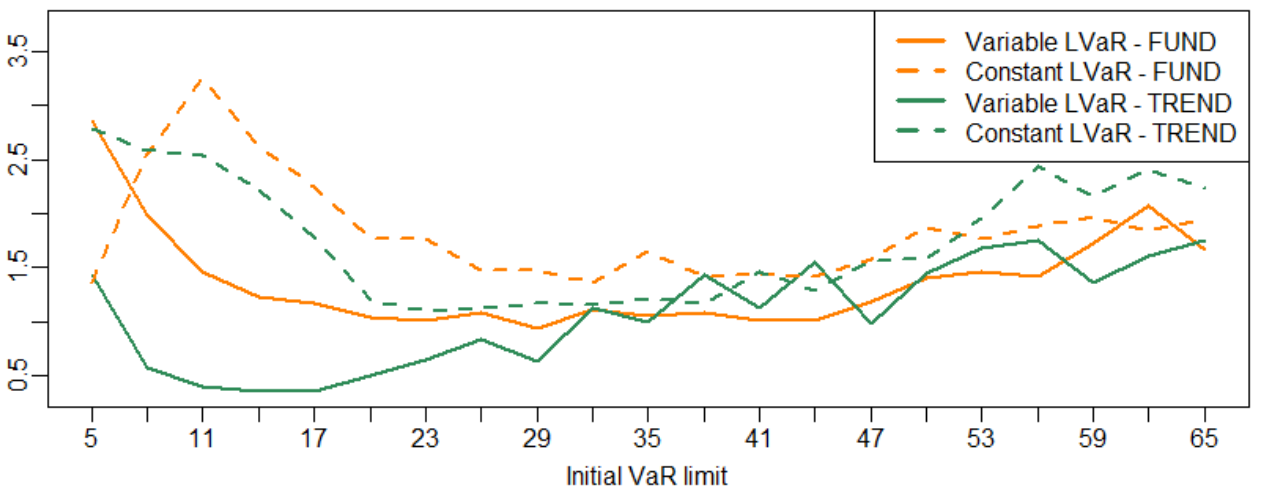

Figure 13 - Evolution of instability indicators when the initial VaR limit increases from 5 to 65. From top to bottom: return volatility, return kurtosis, return Hill tail index, and agent strength index. 
These experiments show that if traders reduce their tolerance to risk during episodes of market turmoil, VaR systems have an even greater potential to heighten market instability. It is important to be aware of this point, because while some investors - such as hedge funds - are able to bear price fluctuations and portfolio losses for a while, other market participants are more risk averse and quickly react to first signs of instability in order to reduce their losses (IMF, 2007); under such circumstances, dynamically reducing VaR limits is a sensible measure at the individual level, but at the collective level the picture looks quite different, as this aggravates the spirals of sales and price drops.

\subsection{Summary of results}

In section 3.2 we have studied the effect of the volatility window used within the VaR model, and have seen that VaR cycles are more likely to appear when traders use a short-term volatility, that is, when a low value for the volatility window is considered. In sections 3.3 and 3.4 we have studied the effect of the VaR limit, and we have seen that the market is most stable when investors use very restrictive or very loose thresholds, while the use of intermediate values of $\mathrm{VaR}$ limit facilitates the emergence of VaR cycles.

In the experiments for the volatility window run in section 3.2, investors always kept the same VaR limit, which took values between $L V a R=30$ and $L V a R=50$. Analogously, in the experiments for the VaR limit run in sections 3.3 and 3.4, investors kept constant their volatility window, which took values between $w^{\sigma}=10$ and $w^{\sigma}=30$. Keeping fixed the rest of parameters has allowed us to clearly identify the effect of the volatility window or the VaR limit.

In this section we provide a broader outlook on the impact of the volatility window and the VaR limit parameters. For instance, we know that the market is more unstable when agents use a short-term volatility, but these results have been obtained for a given range of values for the VaR limit. Is this still true if investors use higher or lower VaR limits? To get a better perspective on the market dynamics obtained for other values of VaR model parameters, we summarise in Figure 14 the behaviour of the different instability indicators when the VaR limit takes values from $L V a R=5$ to $L V a R=65$ and the window volatility takes values from $w^{\sigma}=5$ to $w^{\sigma}=50^{11}$. Figure 15 shows the same graphics for the case of variable VaR limit. In all the contour plots the colour red identifies the most unstable situation (for example, the highest values of volatility or the lowest values of the Hill index).

The graphs in Figure 14 and Figure 15 corroborate the results obtained in sections $3.2-3.4$. Several indicators point out that the most unstable scenario is achieved when investors use a small window to calculate volatility and they moreover use an intermediate VaR limit; return volatility and Hill index are particularly clear in this regard. Moreover, it can be noticed that instability is higher when variable VaR limits are used. For example, in Figure 14 return volatility reaches a maximum value of $30 \%$, whereas in Figure 15, when agents are using variable VaR limits, volatility can rise up to $70 \%$ in the worst case. The same pattern is observed for all indicators.

\footnotetext{
${ }^{11}$ The value of the instability indicators shown in Figure 14 and Figure 15 is an average over 50 runs for each pair of values of VaR limit and volatility window. In the case of the investor strength index, it is an average over the two groups of agents (fundamentalist and technical traders).
} 

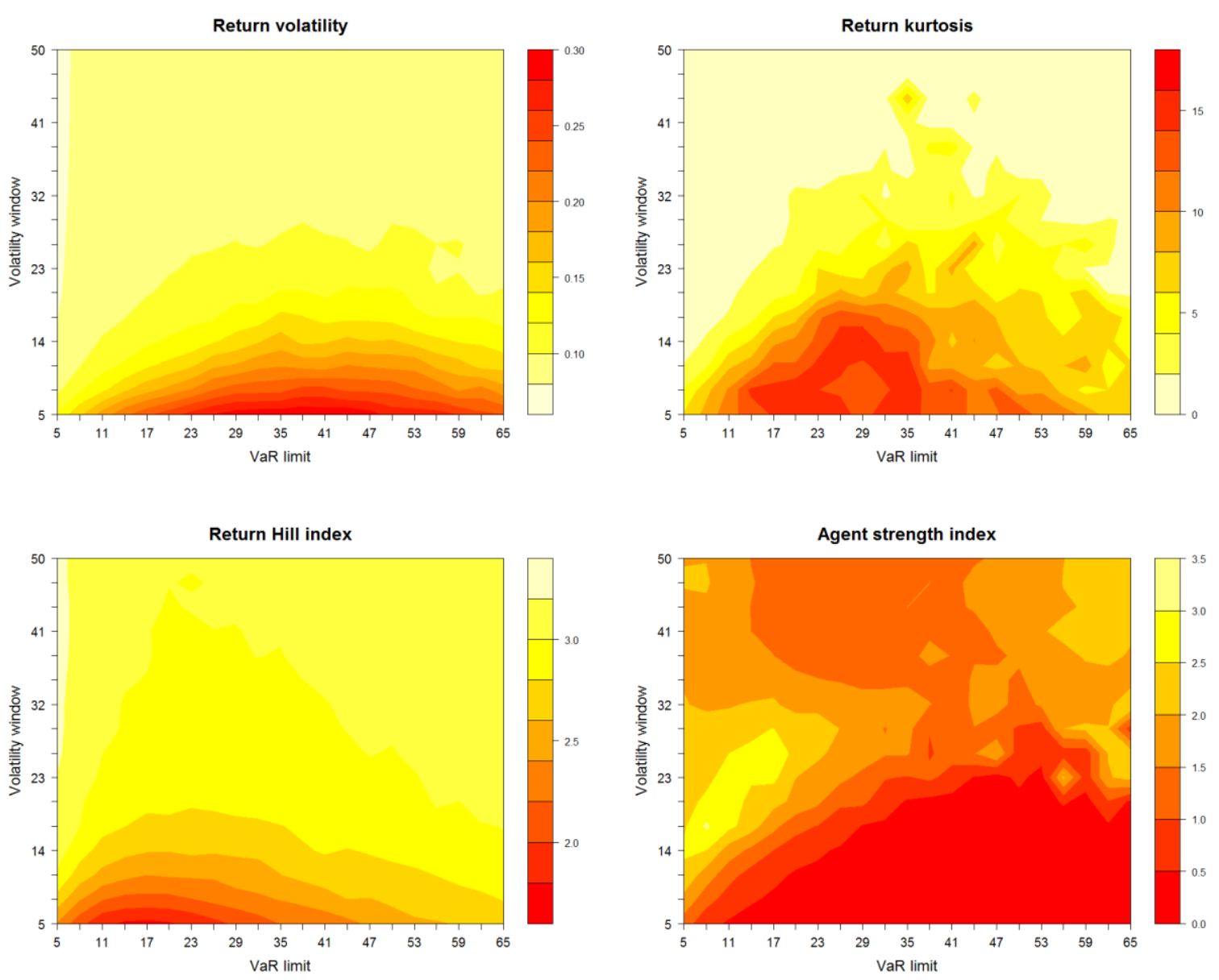

Figure 14 - Graphical summary of instability indicators when the VaR limit (x-axis) increases from 5 to 65 and the volatility window (y-axis) increases from 5 to 50 . Colour red identifies the most unstable situation.
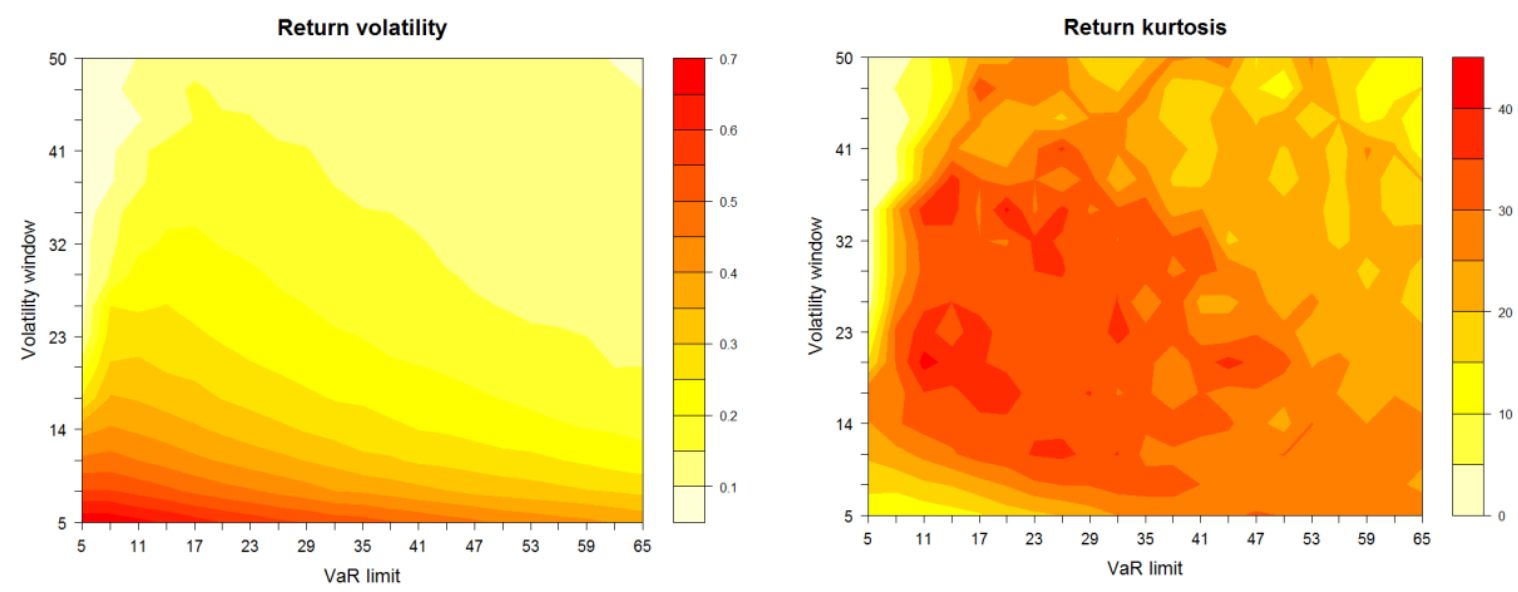

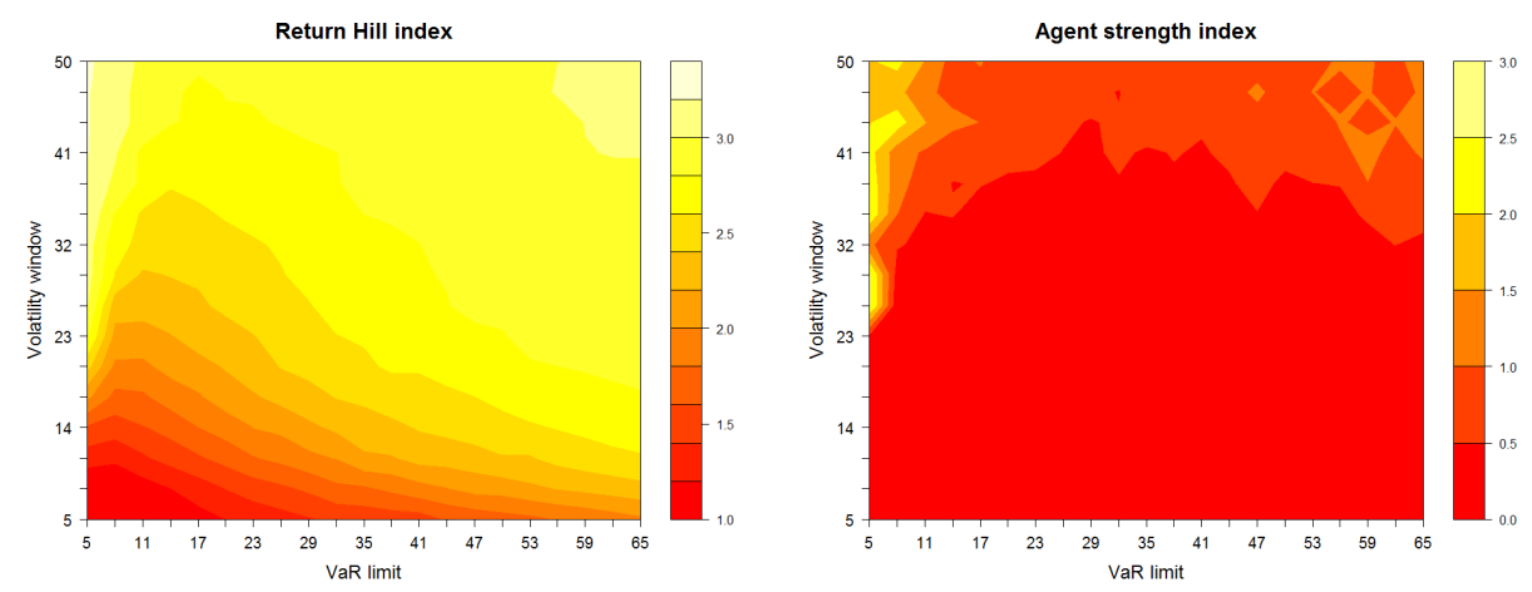

Figure 15 - Graphical summary of instability indicators when the initial VaR limit (x-axis) increases from 5 to 65 and the volatility window (y-axis) increases from 5 to 50. In this case, investors use a variable VaR limit. Colour red identifies the most unstable situation.

\section{Discussion and conclusions}

In recent times the use of risk management systems has become widespread, and VaR has come to be the main methodology at most financial institutions. VaR models assume that risk is exogenous, that is, prices are not affected by actions of financial institutions that are trying to estimate the risk of their portfolio ( (Morris \& Shin, 2000), (Danielsson, et al., 2001)). This is possibly right most of the time, when investors trade with different strategies and criteria; but it is precisely those (even if very rare) occasions when investors act in a uniform way that are of interest, since traders' aggregate action can move the prices and trigger an instability spiral. The use of VaR systems is precisely one of the mechanisms that contribute to homogenise the behaviour of market participants: when - for any reason - volatility goes up, so does the VaR of investors and in case it exceeds the limit, agents are forced to reduce their portfolio at the same time. If, in addition, traders hold similar positions, the way is paved for portfolio reductions to plunge the price, increase the volatility and raise again the traders' VaR. It is therefore a scenario of endogenous risk, since the use of VaR systems has the potential to amplify market instability and feed it back.

In this article we have studied in which circumstances VaR systems do amplify price fluctuations and lead to instability bouts, even in the absence of external shocks. To this aim, we have built an agent-based model, which can capture both the effect that market has on individual investors as well as the global effect that emerges from the aggregation of individual actions. We have considered a model of fundamentalist and technical traders which manage their risk with a simple VaR model and must reduce their positions when the risk of their portfolio goes above a given threshold. We have analised the impact of the widespread use of VaR systems on different financial instability indicators - volatility, return kurtosis, Hill index of returns and trader strength - and we have confirmed that, in a certain number of runs, VaR models induce a particular price dynamics that rises market volatility. These dynamics, which we have called 'VaR cycles', take place when a sufficient number of traders reach their VaR limit and are forced to simultaneously reduce their portfolio; the reductions cause a sudden price movement, 
upsurge volatility and force even more traders to liquidate part of their positions due to the new increase of their VaR. This type of dynamics supports the theory that the generalisation of VaR systems may give rise to vicious circles as claimed e.g. by Persaud (2000) or Danielsson et al. (2001).

Our model has allowed us to analyse the impact, ceteris paribus, of the different parameters of the $\mathrm{VaR}$ model on the instability indicators. The following brief discussion summarises our findings:

- VaR limit: The market is particularly stable when investors set very restrictive or very loose limits for their VaR level. A low VaR threshold heavily constrains the positions that agents can take, and so their VaR-induced reductions have a small effect in market dynamics. On the other hand, if agents set a high VaR threshold, it is less likely that they reach their limit, and so price dynamics do not differ much from the non-VaR scenario. In the light of these results, we might conclude that it would be most appropriate for market stability not to use any risk-management system, or to impose very restrictive standards to market participants. However, both scenarios are unrealistic: the lack of risk-management policies would expose the market to other sources of instability not contemplated in our model; an overly restrictive policy would significantly restrict the trading freedom of market participants, and this has been shown to reduce market efficiency (Takahashi, 2013).

- Volatility window: When agents use a short-term window to calculate volatility, it turns out to be quite sensitive to price movements, and VaR cycles apppear more frequently. Our experiments show that using a medium- or long-term window to calculate volatility highly reduces market instability. These results 'exonerate' Basel Accords from the suspicion of contributing to exacerbate market turmoil, as VaR-based capital requirements are calculated with at least one year of historical data, and so volatility slowly reacts to market movements. However, when $\mathrm{VaR}$ is employed to control the risk of traders' positions, using a short-term window is the usual practice as this allows to promptly react to deteriorating market conditions (Finger, 2009).

- Variable VaR limit: When traders are allowed to dinamically adjust their VaR limit on the basis of market volatility, this aggravates the potentially destabilising effect of VaR systems compared to the constant-limit scenario, because in times of financial turmoil, the reduction of VaR limits adds up to the increase of portfolio VaR and both mechanisms urge traders to further reduce their positions.

While our results indicate that the widespread use of VaR-based risk management systems actually contributes to increase financial instability, this does not mean that this type of systems should no longer be used. The main message to be extracted from our work is that risk managers and regulators must be aware of the endogenous risk and the particular dynamics potentially induced by VaR models and take action to address them. Risk management systems should be combined with other types of measures, such as stress tests. At present, numerous entities conduct stress tests, but they only focus on the individual institution and analyse if the entity, considered in isolation, would be able to withstand a shock; stress tests do not contemplate the fact that entities react to the shock and this has a ripple effect on other institutions - the fragility of some participants can be transmitted to others - and those institutions that were able to weather the initial shock can end up failing (Bookstaber, Cetina, Feldberg, Flood, \& Glasserman, 2013). Stress tests should be able to somehow reflect the two- 
way relationship between market conditions and investor behavior: when market gets more volatile, participants react, and these can worsen market conditions with their own behaviour, originating a spiral of dangerous consequences.

In addition, regulators should consider the homogenising effect that certain policies - such as Basel Accords - create on market participants' behaviour. New regulations should focus not only on the stability of individual institutions, but policy makers should analyse the systemic effect of adopting such regulations and their potential contribution to instabilising spirals before implementing them.

Although we have focused exclusively on the VaR-based risk management systems, the mechanisms we have studied here are essentially the same than those underlying other riskmanagement practices (IMF, 2007). For instance, hedge funds and other leveraged entities borrow from their prime broker, who sets a margin level to hedge against possible losses. Primer brokers often adjust the margin threshold in order to control their own VaR (Brunnermeier \& Pedersen, 2009), and this implies that in moments of heightened volatility hedge funds are forced to post more collateral or reduce their positions, possibly triggering a spiral of sales similar to that described here for VaR systems. For this reason, the market dynamics described in this article go beyond VaR models and constitute an illustration of the potential effects of other risk-management policies.

\section{Acknowledgements}

We would like to thank the editor and the anonymous reviewers for their insightful and constructive comments.

\section{Funding sources}

This research did not receive any specific grant from funding agencies in the public, commercial, or non-for-profit sectors.

\section{References}

Adrian, T., \& Boyarchenko, N. (2012). Intermediary leverage cycles and financial stability. New York: Federal Reserve Bank of New York - Staff report No. 567.

Adrian, T., \& Shin, H. (2013). Procyclical Leverage and Value-at-Risk. New York: Federal Reserve Bank of New York Staff Reports, No. 338. DOI 10.3386/w18943.

Arthur, W., Holland, J., LeBaron, B., Palmer, R., \& Tayler, P. (1996). Asset pricing under endogenous expectations in an artificial stock market. SFI Working Paper, 96-12-093. DOI $10.2139 / \mathrm{ssrn} .2252$. 
Aymanns, C., \& Farmer, J. (2015). The dynamics of the leverage cycle. Journal of Economic Dynamics and Control, 50, 155-179. DOI 10.1016/j.jedc.2014.09.015.

Aymanns, C., Caccioli, F., Farmer, J., \& Tan, V. (2016). Taming the Basel leverage cycle. Journal of Financial Stability, 27, 263-277. DOI 10.1016/j.jfs.2016.02.004.

Bank of England. (2004). Financial stability review - December 2004. Bank of England.

Beck, T., De Jonghe, O., \& Schepens, G. (2011, July 25). Bank competition and stability: Cross-country heterogeneity. Retrieved June 14, 2013, from VOX CEPR's Policy Portal: http://www.voxeu.org/article/bank-competition-and-stability-cross-country-heterogeneity

BIS. (1999). A review of financial markets events in autumn 1998. Basilea: Bank for International Settlements.

Bonenkamp, U. (2010). Combining technical and fundamental trading strategies. Heidelberg: Gabler.

Bookstaber, R. (2012). Using agent-based models for analyzing threats to financial stability. Office of Financial Research.

Bookstaber, R., Cetina, J., Feldberg, G., Flood, M., \& Glasserman, P. (2013). Stress tests to promote financial stability: Assessing progress and looking to the future. Office of Financial Research - Working paper 0010.

Brock, W., \& Hommes, C. (1998). Heterogeneous beliefs and routes to chaos in a simple asset pricing model. Journal of Economic Dynamics and Control, 1235-1274.

Brunnermeier, M., \& Pedersen, L. (2009). Market liquidity and funding liquidity. The Review of Financial Studies, 22(6), 2201-2238. DOI 10.3386/w12939.

Chen, S., \& Yeh, C. (2001). Evolving traders and the business school with genetic programming: A new architecture of the agent-based artificial stock market. Journal of Economic Dynamics and Control, 25, 363-393.

Choudhry, M. (2006). An introduction to value-at-risk. Chichester: John Wiley \& Sons.

Clegg, R. (2006). A practical guide to measuring the Hurst parameter. 21st UK Performance Engineering Workshop, School of Computing Science Technical Report Series, CSTR-916, (pp. 43-55). Newcastle.

Colander, D. (2009). Testimony submitted to the U.S. House of Representatives, Committee on Science and Technology, for the hearing "The risks of financial modeling: VaR and the economic meltdown".

Cont, R. (2001). Empirical properties of asset returns: stylized facts and statistical issues. Quantitative finance, 1, 223-236. DOI 10.1080/713665670.

Cristelli, M. (2014). Complexity in financial markets. Springer.

Danielsson, J., \& Shin, H. (2002). Endogenous risk. http://www.riskresearch.org/files/DanielssonShin2002.pdf. 
Danielsson, J., Embrechts, P., Goodhart, P., Keating, C., Muennich, F., Renault, O., et al. (2001). An academic response to Basel II. LSE Financial Markets Group. DOI 10.3929/ethz-a004259443.

Danielsson, J., Shin, H., \& Zigrand, J. (2004). The impact of risk regulation on price dynamics. Journal of Banking \& Finance, 28(1069-1087). DOI 10.1016/S0378-4266(03)00113-4.

Danielsson, J., Shin, H., \& Zigrand, J. (2009). Risk appetite and endogenous risk.

Davis, E. (1999). A reappraisal of market liquidity risk in the light of the Russia/LTCM global securities market crisis. Workshop on "Empirical research on bank supervision and structure". Amsterdam: Basle Committee on Banking Supervision.

De Grauwe, P., \& Grimaldi, M. (2004). Bubbles and crashes in a behavioural finance model. Sveriges Riksbank working paper series No.164.

Duffy, J., \& Ünver, U. (2006). Asset price bubbles and crashes with near-zero-intelligence traders. Economic Theory, 537-563. DOI 10.1007/s00199-004-0570-9.

ECB. (2007). Financial stability review - June 2007. Frankfurt: European Central Bank.

Einarsson, R. (2013). Reproducing the stylized facts of financial returns. Göteborg: Chalmers University of Technology.

Faria, L. (2012). Financial regulation - part II: Bank's behaviour under Basel III capital requirements using an agent-based model. Policy paper 12/19.

Faria, L., \& Phelps, S. (2011). An investigation of the consequences of Basel III using an agentbased model. The 13th International Conference on Electronic Commerce. Liverpool. 10.1145/2378104.2378131.

Farmer, J., \& Joshi, S. (2002). The price dynamics of common trading strategies. Journal of Economic Behavior and Organization, 49, 149-171. DOI 10.1016/S0167-2681(02)00065-3.

Feridun, M. (2005). Failure of value at risk systems: A case study. European Journal of Economics, Finance and Administrative Sciences, 2(1), 57-67.

Finger, C. (2009). VaR is from Mars, Capital is from Venus. RiskMetrics Group - Research monthly April 2009.

Fostel, A., \& Geanakoplos, J. (2008). Leverage cycles and the anxious economy. American Economic Review, 98(4), 1211-1244. DOI 10.1257/aer.98.4.1211.

Gadanecz, B., \& Jayaram, K. (2008). Measures of financial stability - A review. IFC Bulletin No. 31 .

Geanakoplos, J. (1997). Promises promises. New Haven: Cowles Foundation Paper N.1057.

Geanakoplos, J. (2003). Liquidity, Default, and Crashes: Endogenous Contracts in General Equilibrium. In Advances in Economics and Econometrics: Theory and Application (pp. 170205). New York: Cambridge University Press. 
Geanakoplos, J. (2009). The leverage cycle. In D. Acemoglu, K. Rogoff, \& M. Woodford, NBER Macroeconomics Annual 2009 (pp. 1-65). University of Chicago Press.

Haldane, A., \& May, R. (2011). Systemic risk in banking ecosystems. Nature, 469, 351-355. DOI 10.1038/nature09659.

Hermsen, O. (2010). Does Basel II destabilize financial markets? An agent-based financial market perspective. The European Physical Journal B, 73, 29-40. DOI 10.1140/epjb/e200900382-1.

Hoelle, M. (2016). The effects of dependent beliefs on endogenous leverage.

IMF. (2007). Global financial stability report - October 2007. Washington D.C.: International Monetary Fund.

Johnson, N., Jefferies, P., \& Ming Hui, P. (2003). Financial market complexity. New York: Oxford University Press.

Jorion, P. (2001). Value at risk: The new benchmark for managing financial risk. New York: McGraw-Hill.

Jorion, P. (2002). Fallacies about the effects of market risk management systems. Financial Stability Review - December 2002, 115-127.

Kestner, L. (2003). Quantitative trading strategies. New York: McGraw-Hill.

Llacay, B. (2015). El impacto de las técnicas VaR en los mercados financieros. Enfoque basado en la simulación multiagente. $\mathrm{PhD}$ Thesis, Universitat de Barcelona.

Lux, T. (1995). Herd behaviour, bubbles and crashes. The Economic Journal, 105(431), 881896.

Lux, T., \& Marchesi, M. (2000). Volatility clustering in financial markets: A microsimulation of interacting agents. International Journal of Theoretical and Applied Finance, 3(4), 675-702. DOI 10.1142/S0219024900000826.

MacKenzie, D. (2003). Long-Term Capital Management and the Sociology of Arbitrage. Economy and Society, 32, 349-380. DOI 10.1080/03085140303130.

Madhavan, A. (2000). Market microstructure: A survey. Los Angeles: Marshall School of Business.

Malkiel, B. (1973). A random walk down Wall Street. Nueva York: Norton.

Manamperi, N. (2013). A comparative analysis of US financial stress indicators. Lubbock: Texas Tech University.

McNeil, A., Frey, R., \& Embrechts, P. (2005). Quantitative risk management: Concepts, techniques, and tools. Princeton: Princeton University Press.

Milton, A. (2016, June 3). Day trading with Donchian channels. Retrieved February 20, 2017, from The balance: https://www.thebalance.com/day-trading-with-donchian-channels-1031186 
Morris, S., \& Shin, H. (2000). Market risk with interdependent choice. Conference on liquidity risk. Frankfurt.

Murphy, J. (1999). Technical analysis of the financial markets. Paramus: New York Institute of Finance.

O'Neill, B. (2011). Fundamentals of the stock market. McGraw-Hill.

Pericoli, M., \& Sbracia, M. (2010). Crowded trades among hedge funds. Working paper.

Perold, A. (1999). Long-Term Capital Management, L.P. Boston: Harvard Business School Publishing.

Persaud, A. (2000). Sending the herd off the cliff edge: The disturbing interaction between herding and market-sensitive risk management practices. ERisk, 1-6. DOI 10.1108/eb022947.

Peters, E. (2014). Stable vs. unstable markets: A tale of two states. First Quadrant.

Rebonato, R. (2007). Plight of the fortune tellers: Why we need to manage financial risk differently. Princeton: Princeton University Press.

Saita, F. (2007). Value at risk and bank capital management. San Diego: Academic Press.

Shin, H. (2010). Risk and liquidity. Oxford: Oxford University Press.

Takahashi, H. (2013). Analyzing the influence of Value at Risk on financial markets through agent-based modeling. International Journal of Knowledge-based and Intelligent Engineering Systems, 17, 257-266. DOI 10.3233/KES-130276.

Tasca, P., \& Battiston, S. (2012). Market procyclicality and systemic risk. Zurich: ETH Risk Center - Working Paper ETH-RC-12-012.

Taylor, M. (2009). What is sensitivity analysis? What is...? series, 1-8.

Taylor, S. (2005). Asset price dynamics, volatility, and prediction. Princeton: Princeton University Press.

ten Broeke, G., van Voorn, G., \& Ligtenberg, A. (2016). Which Sensitivity Analysis Method Should I Use for My Agent-Based Model? Journal of Artificial Societies and Social Simulation, 19(1). DOI 0.18564/jasss.2857.

The World Bank. (2013). Global financial development report - Financial stability. Retrieved May 24, 2013, from Key terms explained: http://go.worldbank.org/EXTW5ZJ4C0

Thurner, S. (2011). Systemic financial risk: agent based models to understand the leverage cycle on national scales and its consequences. OECD.

Thurner, S., Farmer, J., \& Geanakoplos, J. (2012). Leverage causes fat tails and clustered volatility. Quantitative Finance, 12(5), 695-707. DOI 10.1080/14697688.2012.674301.

Triana, P. (2010, December 1). VaR: The number that killed us. Futures Mag.

Trichet, J. (2011). Intellectual challenges to financial stability analysis in the era of macroprudential oversight. Financial Stability Review No. 15 - Banque de France. 
Tsay, R. (2005). Analysis of financial time series (Second ed.). Hoboken: John Wiley \& Sons. DOI 10.1002/0471746193.

Westerhoff, F. (2009). A simple agent-based financial market model: Direct interactions and comparisons of trading profits. BERG working paper series on government and growth, No.61.

Whitehead, C. (2013). Destructive coordination. Cornell Law Review, 96, 323-364.

\section{Appendix A: Robustness analysis}

One difficulty associated to agent-based models is the calibration of the usually numerous set of parameters against real data (Thurner, 2011). In this section we analyse the robustness of the model results with respect to changes in parameter values. To this aim, we perform a sensitivity analysis using the one-factor-at-a-time methodology (ten Broeke, van Voorn, \& Ligtenberg, 2016), varying one parameter at a time to observe its impact on results.

We use an extreme case analysis (Taylor M. , 2009) where we choose an upper and lower bound for each parameter and re-run the experiments to compare the results with the base case shown in section 3. The extreme bounds have been selected as the lowest and highest values of each parameter (1) that make sense (e.g., the long-term window used by technical traders cannot be smaller than the short-term window), and (2) for which the basic model where agents use no VaR still satisfies the stylised facts described in section 2.2.5.

Next, we repeat the experiments done in sections 3.1-3.4 for the three values of parameters: the base value, the lower bound and the upper bound. In Figure A. 1-Figure A. 11 we provide a summary of the results: to avoid repetitive figures we only show the effect on return volatility as the other instability indicators behave similarly; we have moreover opted for representing only the mean of this indicator (instead of the entire boxplot as in Figure 5, Figure 11-Figure 13) because this allows to neatly present the results under the three scenarios - base, low, and high value of each parameter - on a single graph and facilitates their comparison. As it can be seen below, it turns out that results are robust to other parameter choices, as Figure A. 1-Figure A. 11 show the same qualitative behaviour than those shown in section 3 .

Table 2 summarises the value of all the parameters used in the robustness analyses shown in Figure A. 1 - Figure A. 11.

\begin{tabular}{ccccl}
\hline Parameter & $\begin{array}{c}\text { Base } \\
\text { value }\end{array}$ & $\begin{array}{c}\text { Lower } \\
\text { bound }\end{array}$ & $\begin{array}{c}\text { Upper } \\
\text { bound }\end{array}$ & \multicolumn{1}{c}{ Parameter description } \\
\hline \hline$\lambda$ & 400 & 350 & 450 & Liquidity \\
\hline$\sigma_{P}$ & 0.4 & 0 & 0.7 & $\begin{array}{l}\text { Standard deviation for random term } \\
\text { in price formation }\end{array}$ \\
\hline$N_{F U N D}$ & 200 & 150 & 250 & Number of fundamentalist traders \\
\hline
\end{tabular}




\begin{tabular}{|c|c|c|c|c|}
\hline$N_{\text {TREND }}$ & 200 & 150 & 250 & Number of technical traders \\
\hline$\sigma_{V}$ & 0.25 & 0 & 0.5 & $\begin{array}{l}\text { Standard deviation for random term } \\
\text { in fundamental value formation }\end{array}$ \\
\hline$\left[v_{\min }, v_{\max }\right]$ & {$[-8,8]$} & {$[-0.5,0.5]$} & {$[-20,20]$} & $\begin{array}{l}\text { Boundaries of the uniform } \\
\text { distribution that sets the difference } \\
\text { between the fundamental value and } \\
\text { the value perceived by each } \\
\text { fundamentalist trader }\end{array}$ \\
\hline$\left[T_{\min }, T_{\max }\right]$ & {$[2,5]$} & {$[1,4]$} & {$[7,10]$} & $\begin{array}{l}\text { Boundaries of the uniform } \\
\text { distribution that sets the entry } \\
\text { thresholds of fundamentalist traders }\end{array}$ \\
\hline$\left[\tau_{\min }, \tau_{\max }\right]$ & {$[-0.5,1]$} & {$[-1.5,0]$} & {$[0.5,2]$} & $\begin{array}{l}\text { Boundaries of the uniform } \\
\text { distribution that sets the exit } \\
\text { thresholds of fundamentalist traders }\end{array}$ \\
\hline$\left[w_{S, \min }^{t r}, w_{S, \max }^{t r}\right]$ & {$[5,15]$} & {$[2,12]$} & {$[10,20]$} & $\begin{array}{l}\text { Boundaries of the uniform } \\
\text { distribution that sets the window of } \\
\text { short-term moving average used by } \\
\text { technical traders }\end{array}$ \\
\hline$\left[w_{L, \min }^{t r}, w_{L, \max }^{t r}\right]$ & {$[35,50]$} & {$[20,35]$} & {$[60,75]$} & $\begin{array}{l}\text { Boundaries of the uniform } \\
\text { distribution that sets the window of } \\
\text { long-term moving average used by } \\
\text { technical traders }\end{array}$ \\
\hline$\left[w_{C, \min }^{t r}, w_{C, \max }^{t r}\right]$ & {$[5,30]$} & {$[1,26]$} & {$[15,40]$} & $\begin{array}{l}\text { Boundaries of the uniform } \\
\text { distribution that sets the window of } \\
\text { exit channel used by technical } \\
\text { traders }\end{array}$ \\
\hline
\end{tabular}

Table 2 - Table of parameters used in the simulations 


\section{Robustness for parameter $\lambda$}
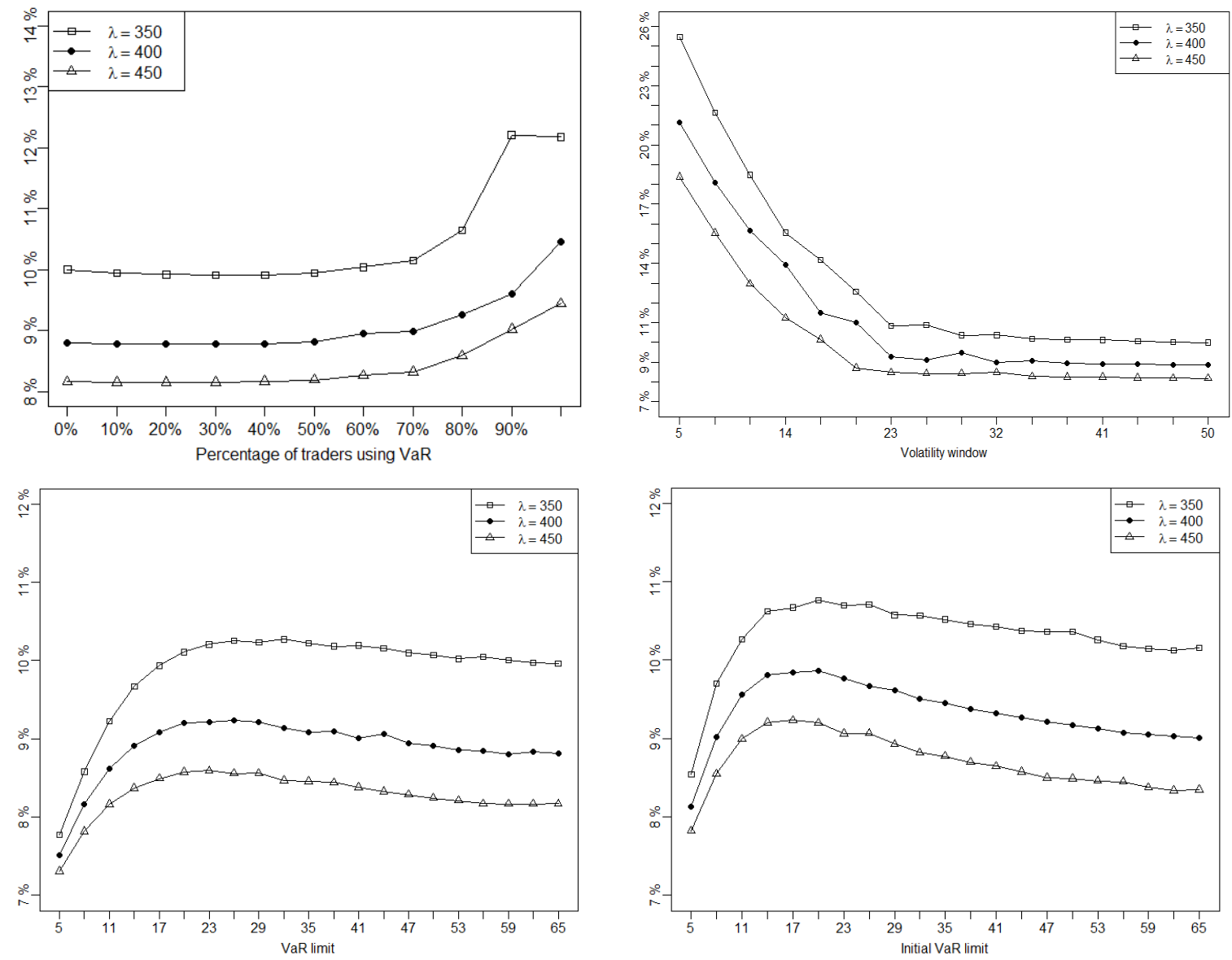

Figure A. 1 -Evolution of return volatility for different values of parameter $\lambda$. Top left: The percentage of agents using VaR increases from $0 \%$ to $100 \%$. Top right: The volatility window increases from 5 to 50 .

Bottom left: The VaR limit is constant and increases from 5 to 65 . Bottom right: The VaR limit is variable and its initial value increases from 5 to 65 . 


\section{Robustness for parameter $\sigma_{P}$}
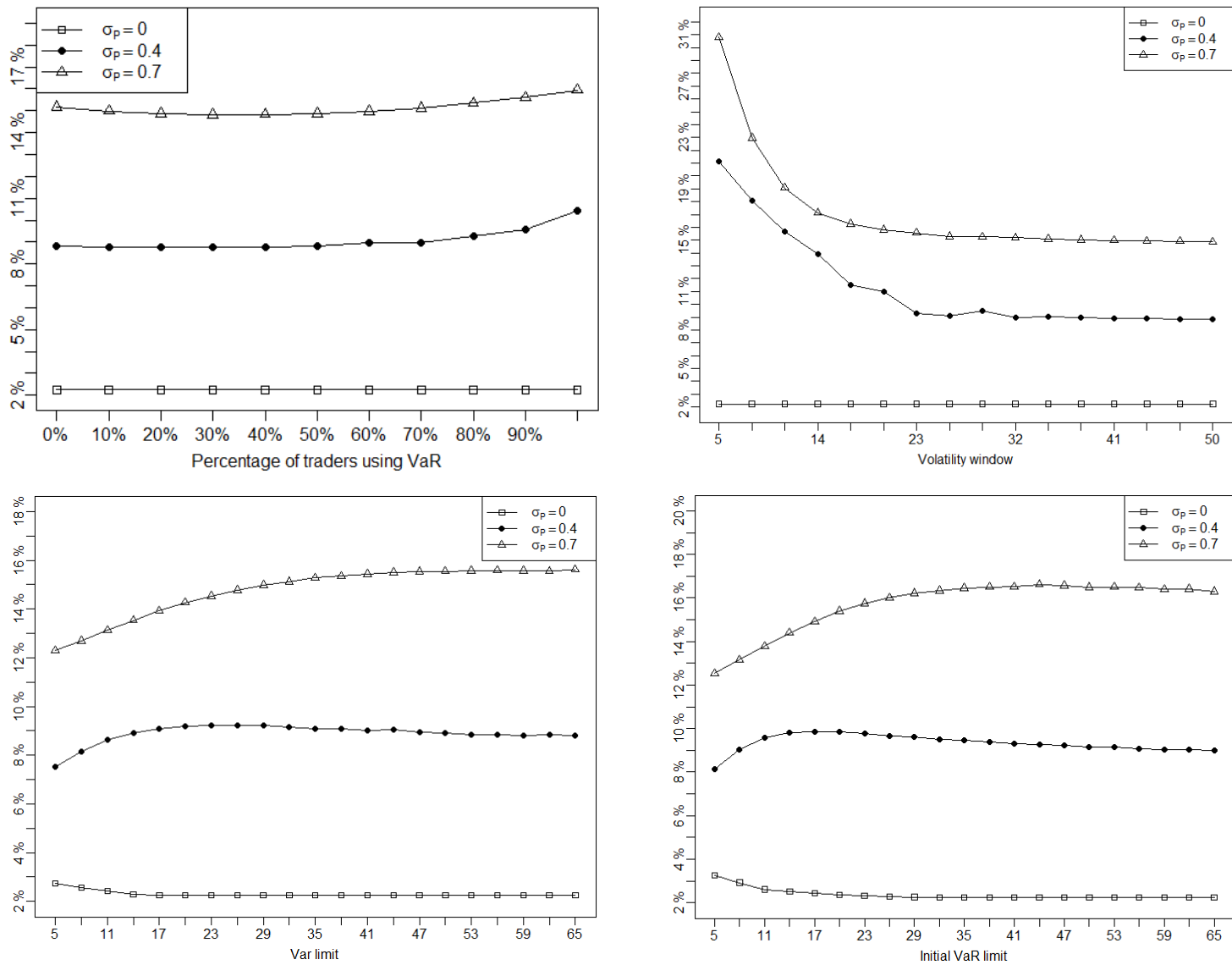

Figure A. 2 - Evolution of return volatility for different values of parameter $\sigma_{P}$. Top left: The percentage of agents using VaR increases from $0 \%$ to $100 \%$. Top right: The volatility window increases from 5 to 50 . Bottom left: The VaR limit is constant and increases from 5 to 65 . Bottom right: The VaR limit is variable and its initial value increases from 5 to 65 . 
Robustness for parameter $N_{F U N D}$
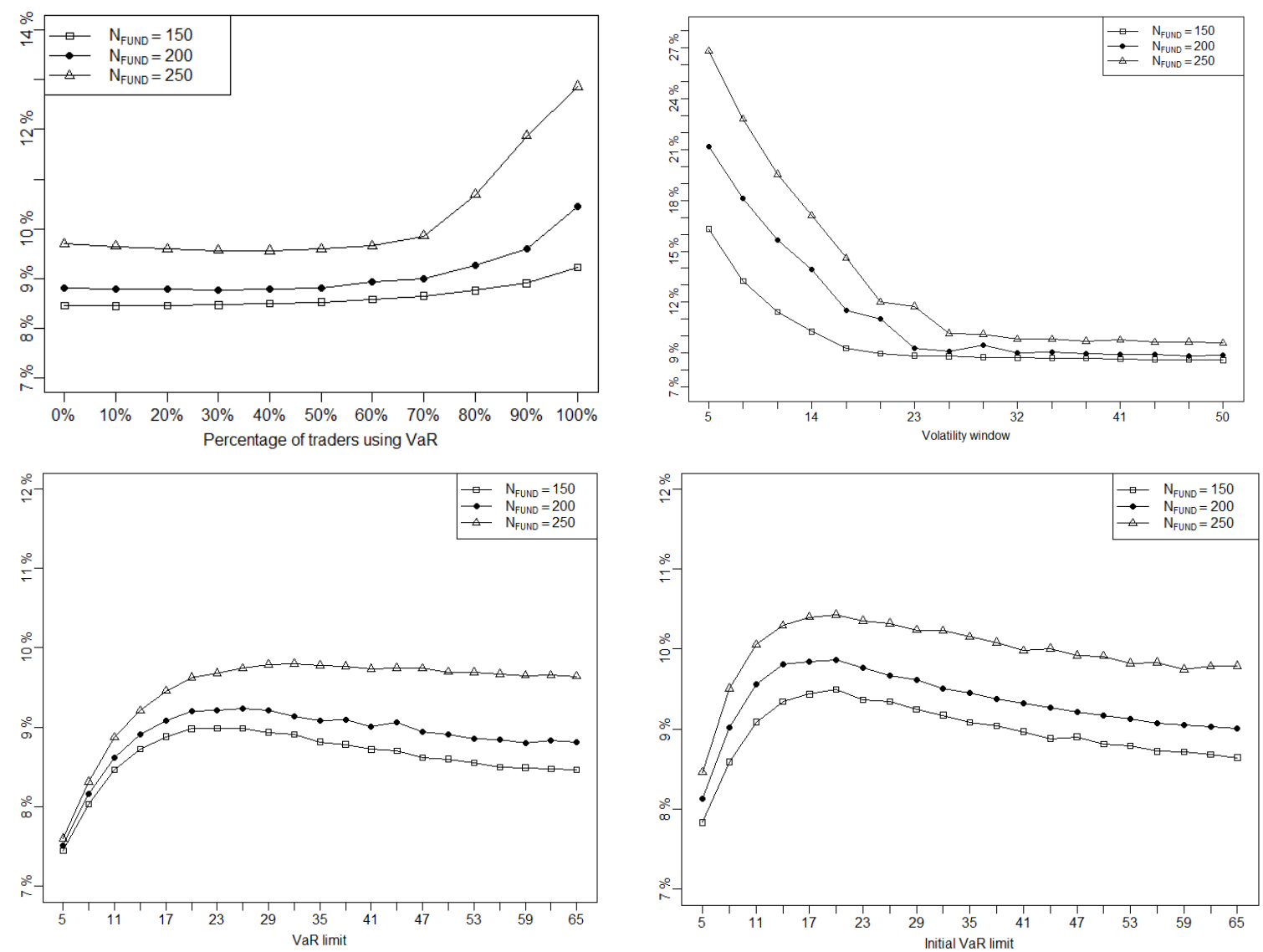

Figure A. 3 - Evolution of return volatility for different values of parameter $N_{F U N D}$. Top left: The percentage of agents using VaR increases from $0 \%$ to $100 \%$. Top right: The volatility window increases from 5 to 50. Bottom left: The VaR limit is constant and increases from 5 to 65 . Bottom right: The VaR limit is variable and its initial value increases from 5 to 65 . 
Robustness for parameter $N_{\text {TREND }}$
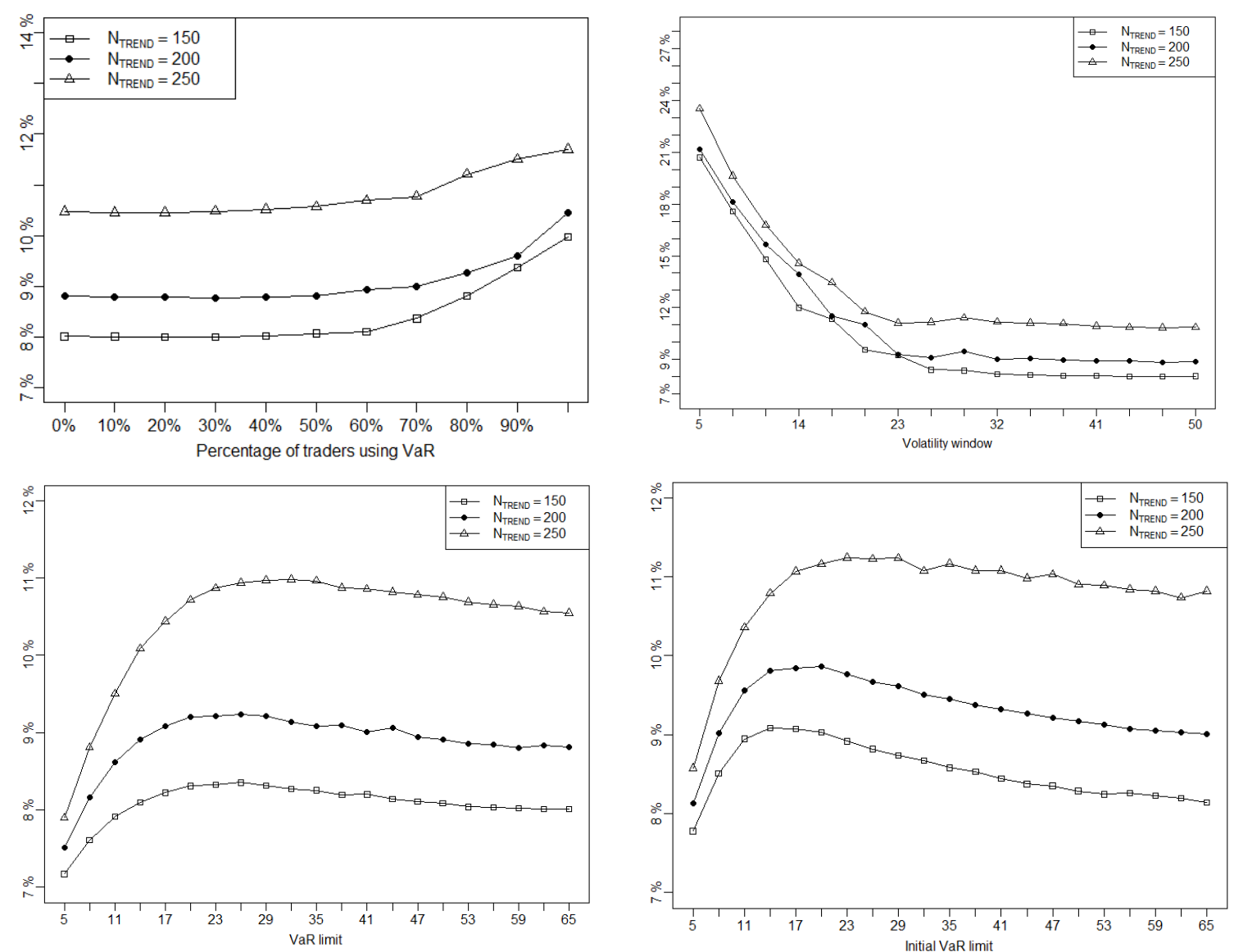

Figure A. 4 - Evolution of return volatility for different values of parameter $N_{\text {TREND }}$. Top left: The percentage of agents using VaR increases from $0 \%$ to $100 \%$. Top right: The volatility window increases from 5 to 50. Bottom left: The VaR limit is constant and increases from 5 to 65 . Bottom right: The VaR limit is variable and its initial value increases from 5 to 65 . 


\section{Robustness for parameter $\sigma_{V}$}
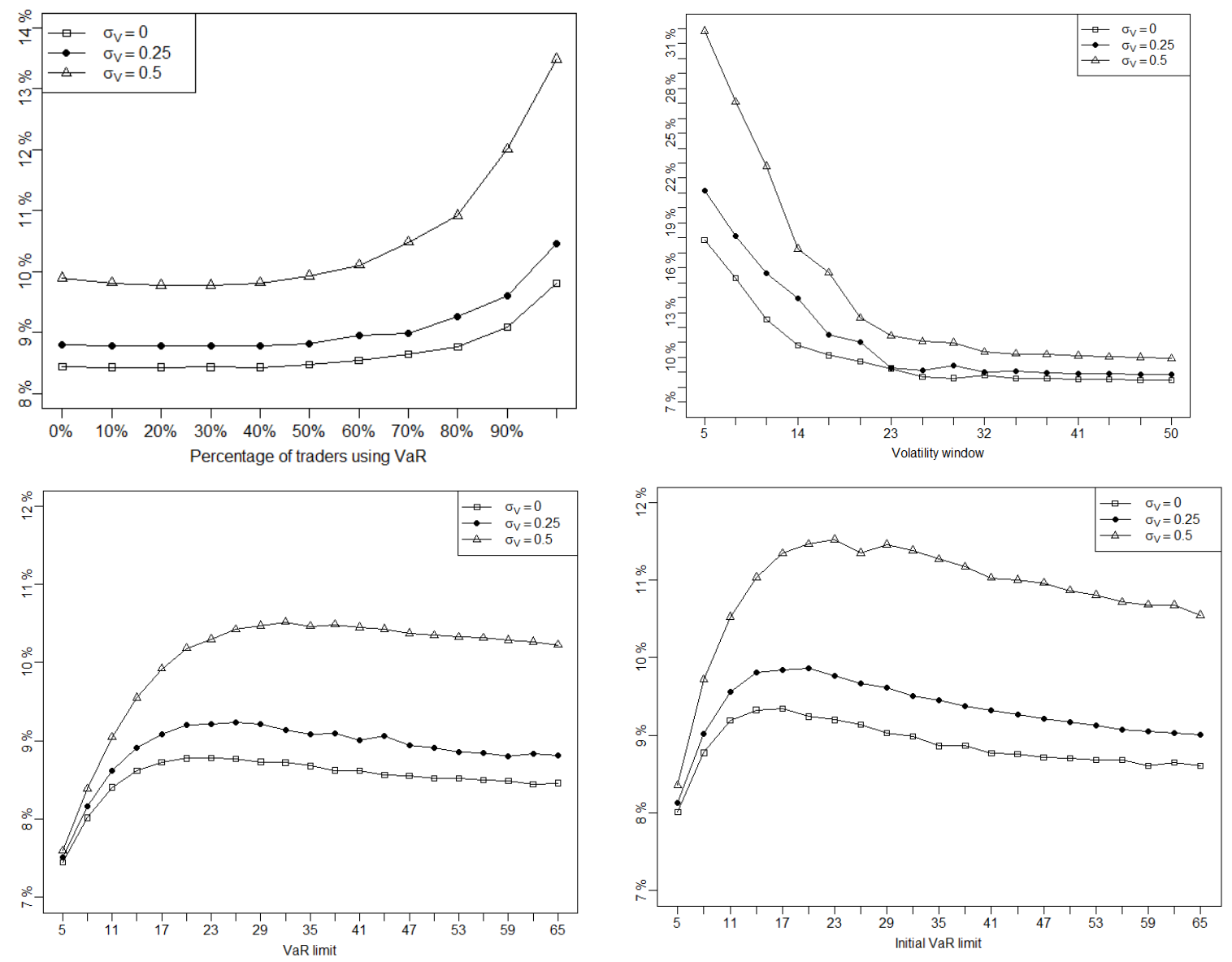

Figure A. 5 - Evolution of return volatility for different values of parameter $\sigma_{V}$. Top left: The percentage of agents using VaR increases from $0 \%$ to $100 \%$. Top right: The volatility window increases from 5 to 50 . Bottom left: The VaR limit is constant and increases from 5 to 65 . Bottom right: The VaR limit is variable and its initial value increases from 5 to 65 .

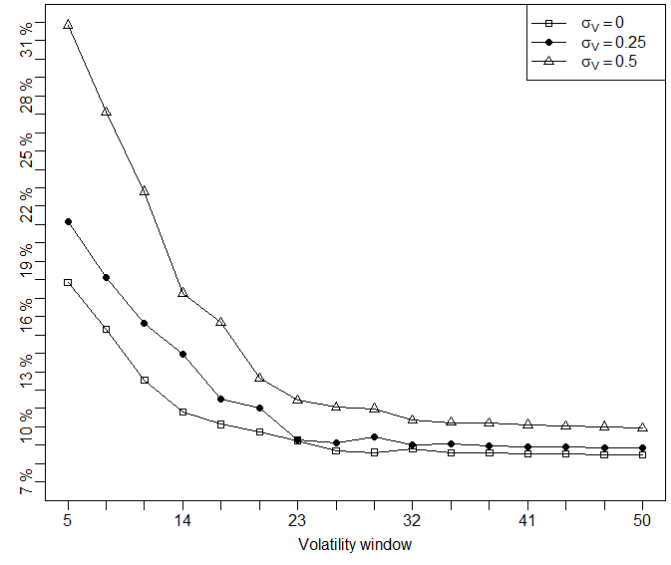

(1)


Robustness for parameters $\left[v_{\min }, v_{\max }\right]$
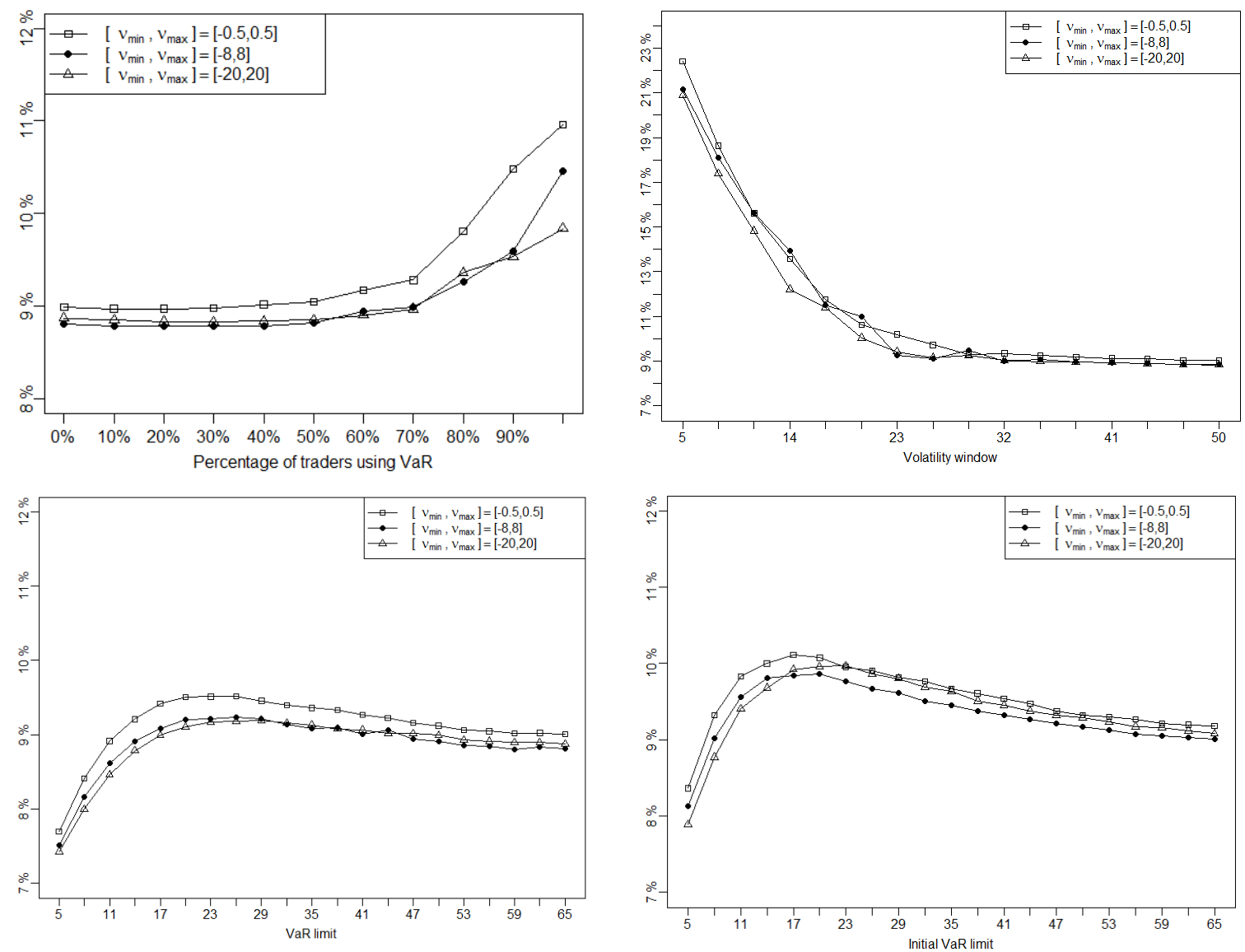

Figure A. 6 - Evolution of return volatility for different values of parameters $\left[v_{\min }, v_{\max }\right]$. Top left: The percentage of agents using $\mathrm{VaR}$ increases from $0 \%$ to $100 \%$. Top right: The volatility window increases from 5 to 50 . Bottom left: The VaR limit is constant and increases from 5 to 65 . Bottom right: The VaR limit is variable and its initial value increases from 5 to 65 . 
Robustness for parameters $\left[T_{\min }, T_{\max }\right]$
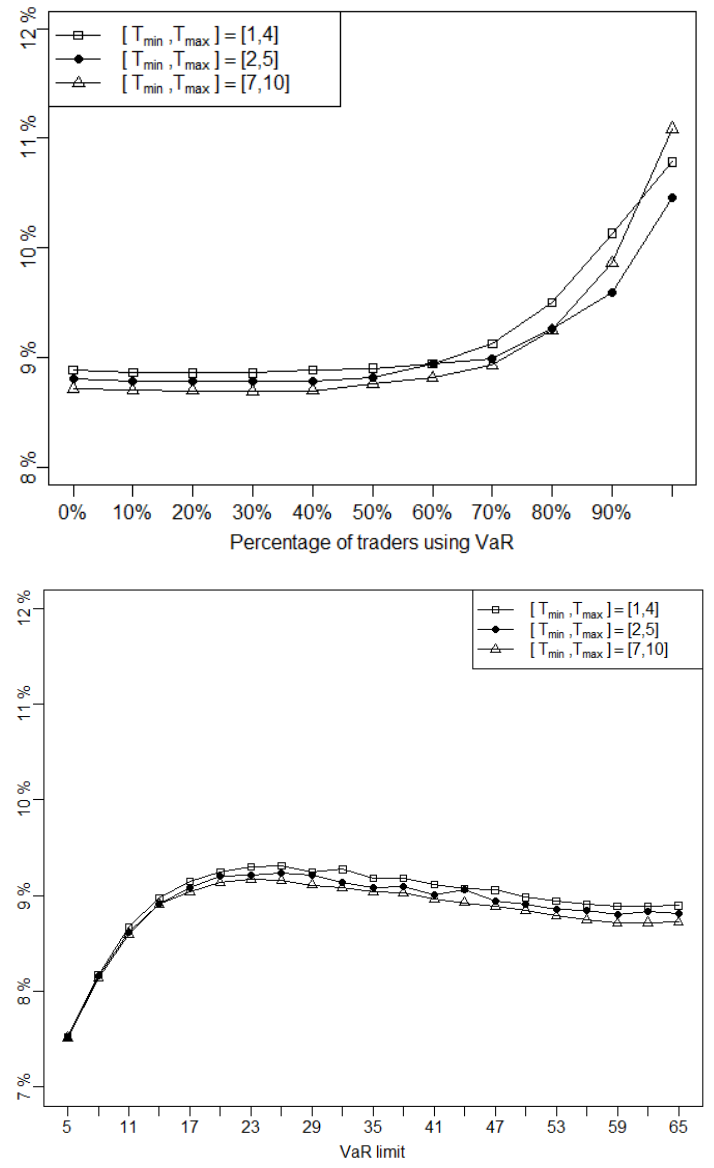
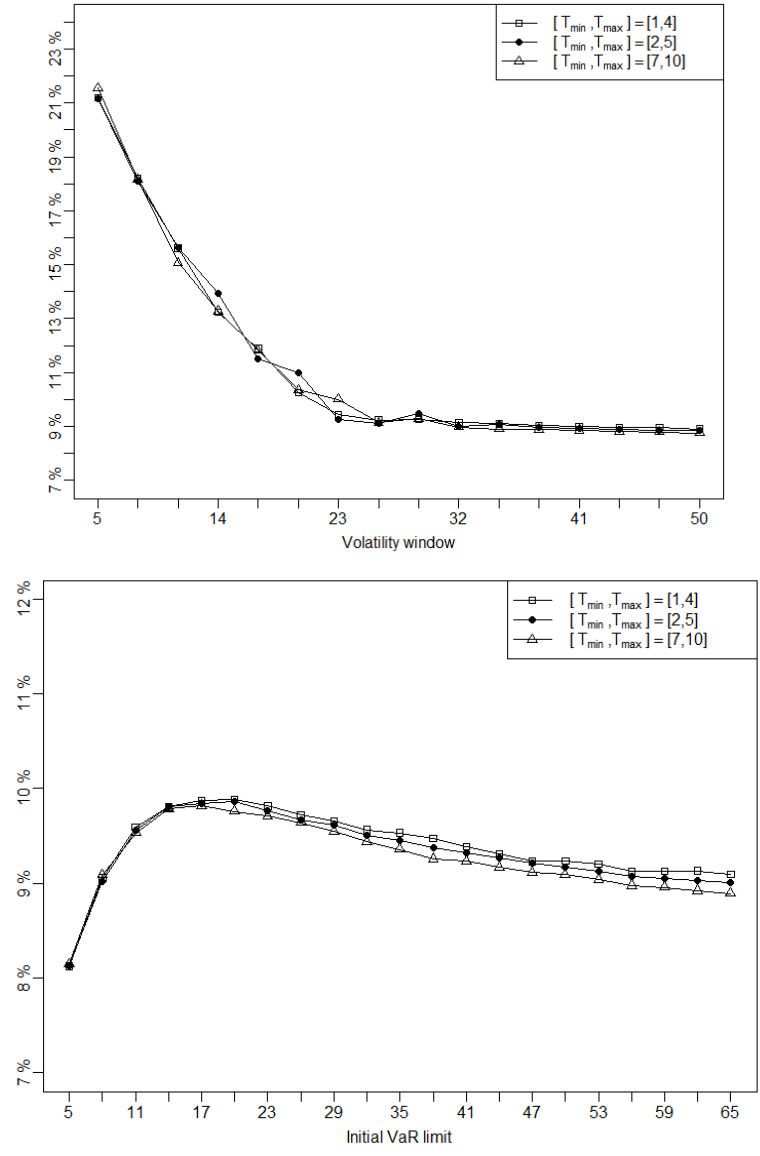

Figure A. 7 - Evolution of return volatility for different values of parameters $\left[T_{\min }, T_{\max }\right]$. Top left: The percentage of agents using $\mathrm{VaR}$ increases from $0 \%$ to $100 \%$. Top right: The volatility window increases from 5 to 50. Bottom left: The VaR limit is constant and increases from 5 to 65 . Bottom right: The VaR limit is variable and its initial value increases from 5 to 65 . 
Robustness for parameters $\left[\tau_{\min }, \tau_{\max }\right]$
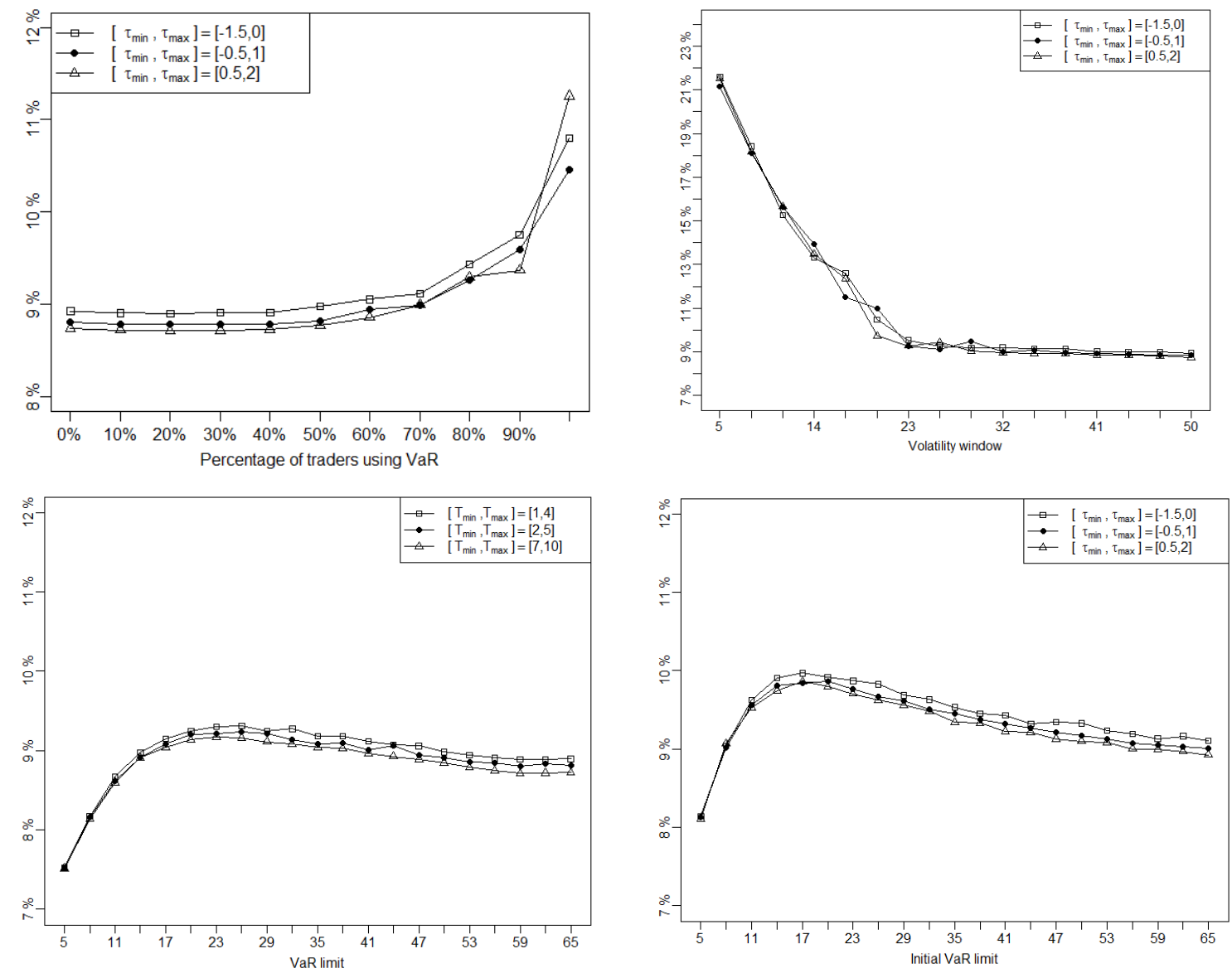

Figure A. 8 - Evolution of return volatility for different values of parameters $\left[\tau_{\min }, \tau_{\max }\right]$. Top left: The percentage of agents using $\mathrm{VaR}$ increases from $0 \%$ to $100 \%$. Top right: The volatility window increases from 5 to 50 . Bottom left: The VaR limit is constant and increases from 5 to 65 . Bottom right: The VaR limit is variable and its initial value increases from 5 to 65 . 
Robustness for parameters $\left[w_{S, \min }^{t r}, w_{S, \max }^{t r}\right]$
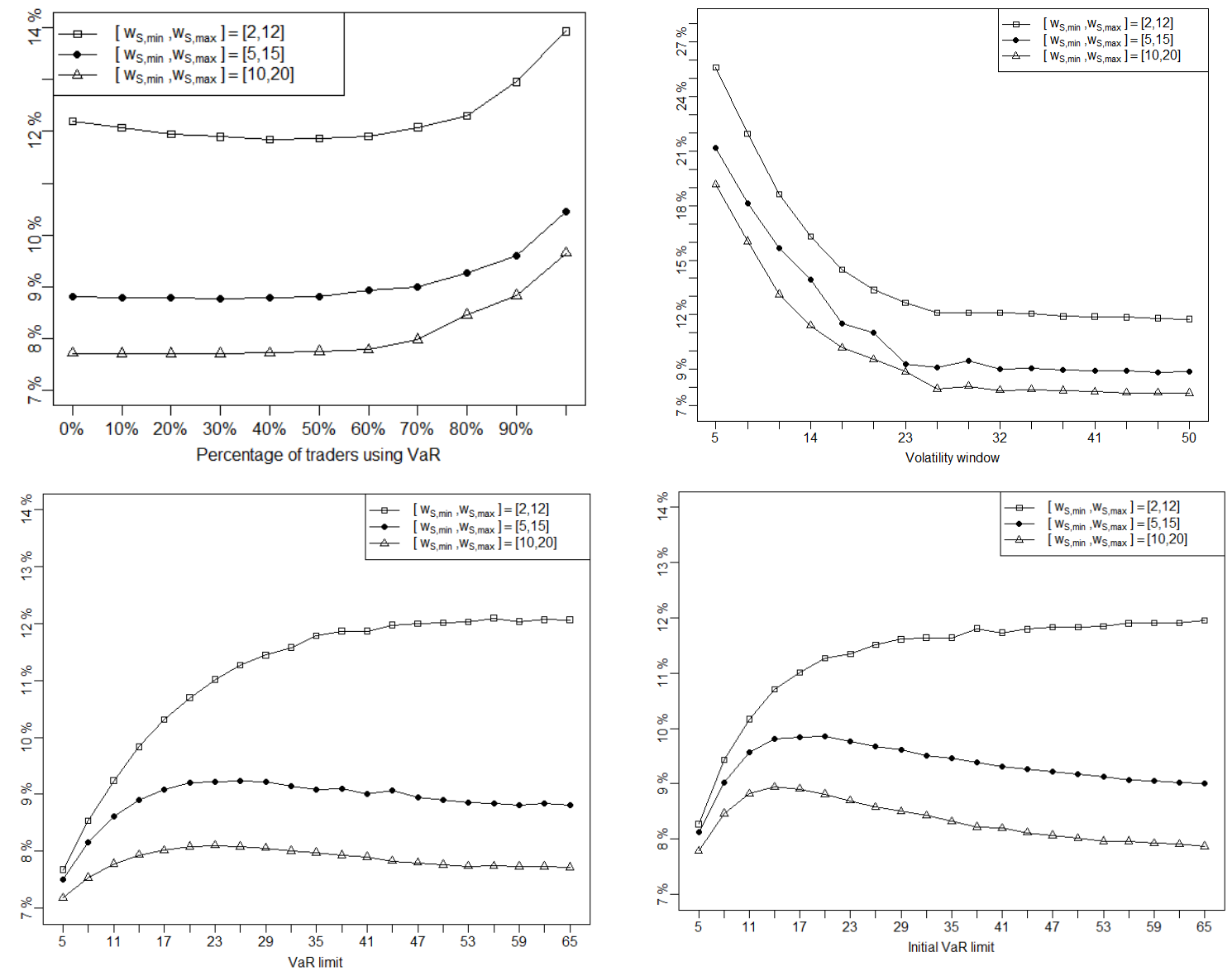

Figure A. 9 - Evolution of return volatility for different values of parameters $\left[w_{S, \min }^{t r}, w_{S, \max }^{t r}\right]$. Top left: The percentage of agents using VaR increases from $0 \%$ to $100 \%$. Top right: The volatility window increases from 5 to 50 . Bottom left: The VaR limit is constant and increases from 5 to 65 . Bottom right: The VaR limit is variable and its initial value increases from 5 to 65 . 
Robustness for parameters $\left[w_{L, \min }^{t r}, w_{L, \max }^{t r}\right]$
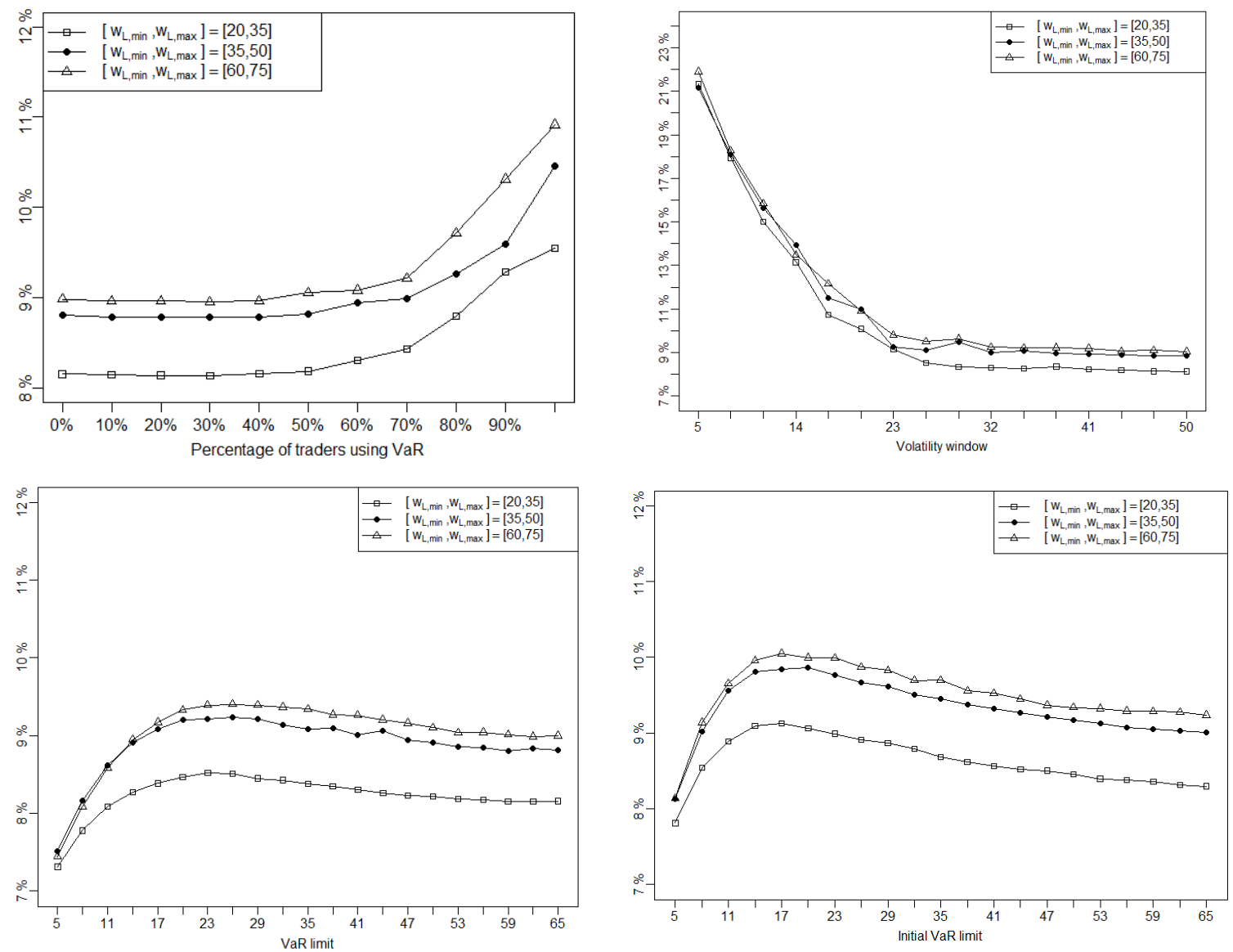

Figure A. 10 - Evolution of return volatility for different values of parameters $\left[w_{L, \min }^{t r}, w_{L, \max }^{t r}\right]$. Top left: The percentage of agents using VaR increases from $0 \%$ to $100 \%$. Top right: The volatility window increases from 5 to 50. Bottom left: The VaR limit is constant and increases from 5 to 65. Bottom right: The VaR limit is variable and its initial value increases from 5 to 65 . 
Robustness for parameters $\left[w_{C, \min }^{t r}, w_{C, \max }^{t r}\right]$
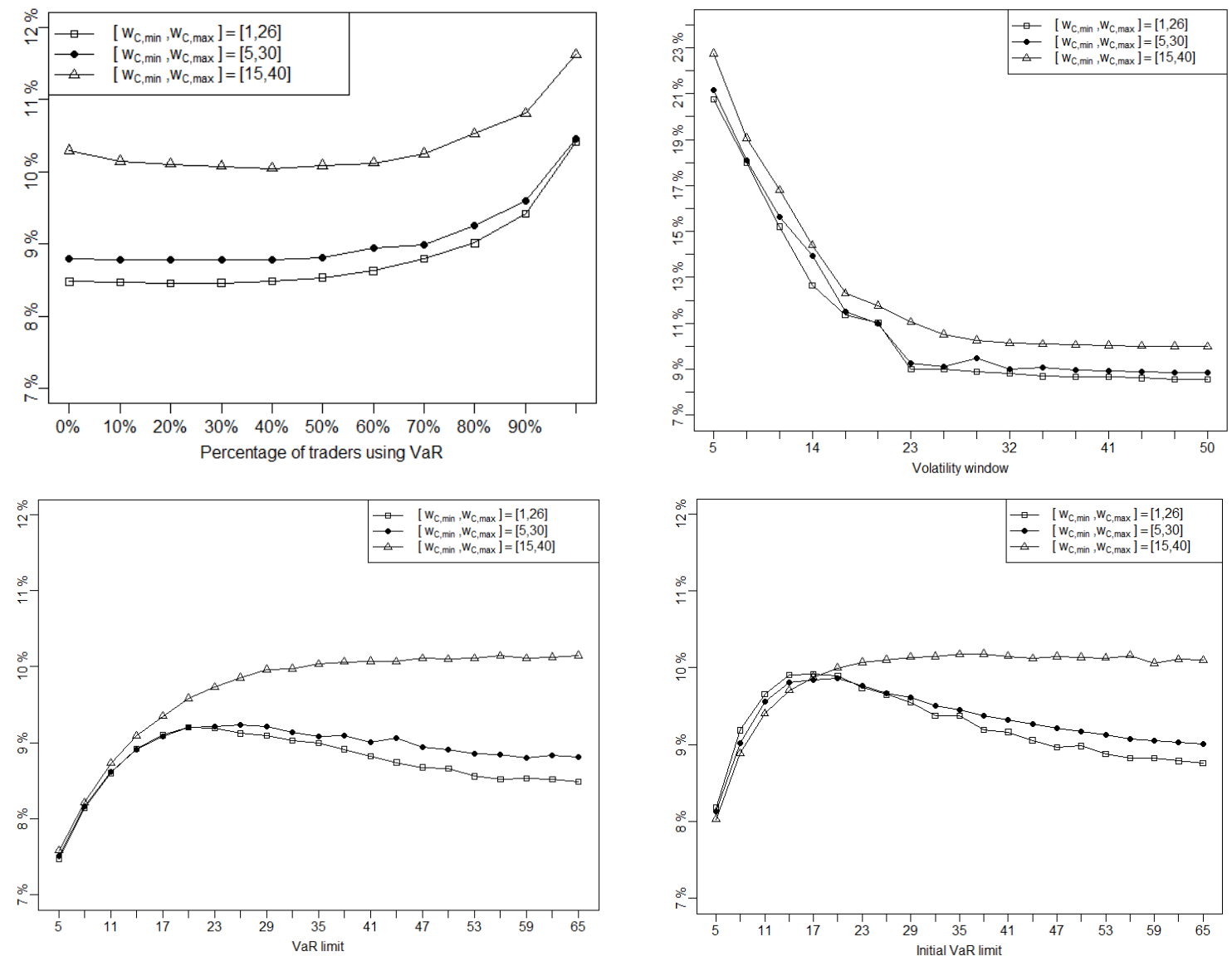

Figure A. 11 - Evolution of return volatility for different values of parameters $\left[w_{C, \min }^{t r}, w_{C, \max }^{t r}\right]$. Top left: The percentage of agents using VaR increases from $0 \%$ to $100 \%$. Top right: The volatility window increases from 5 to 50 . Bottom left: The VaR limit is constant and increases from 5 to 65 . Bottom right: The VaR limit is variable and its initial value increases from 5 to 65 . 